NBSIR 75.741

Mechanistic Studies of

Triphenylphosphine Oxide-Poly

(Ethyleneterephthalate) and Related

Flame Retardant Systems

J. W. Hastie and C. L. McBee

Institute for Materials Research

National Bureau of Standards

Washington, D. C. 20234

August 1975

Final

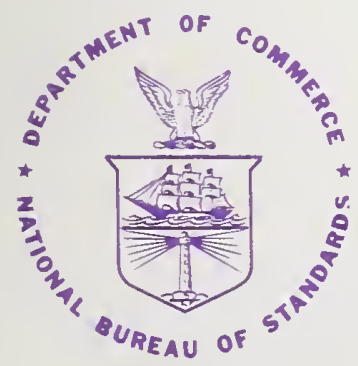

U.S. DEPARTMENT OF COMMERCE

NATIONAL BUREAU OF STANDARDS 
NBSIR 75-741

MECHANISTIC STUDIES OF

TRIPHENYLPHOSPHINE OXIDE-POLY

(ETHYLENETEREPHTHALATE) AND RELATED

FLAME RETARDANT SYSTEMS

J. W. Hastie and C. L. McBee

Institute for Materials Research

National Bureau of Standards

Washington, D. C. 20234

August 1975

Final

U.S. DEPARTMENT OF COMMERCE, Rogers C.B. Morton, Secretary John K. Tabor, Under Secretary

Dr. Betsy Ancker-Johnson, Assistant Secretary for Science and Technology

NATIONAL BUREAU OF STANDARDS. Emest Ambler, Acting Diroctor 


\title{
MECHANISTIC STUDIES OF TRIPHENYLPHOSPHINE OXIDE-POLY (ETHYLENETEREPHTHALATE) AND RELATED FLAME RETARDANT SYSTEMS
}

\author{
J. W. Hastie and C. I. MCBeet \\ Inorganic Chemistry Section \\ Institute for Materials Research \\ National Bureau of Standards \\ Washington, D. C. 20234
}

\section{INTRODUCTION}

Phosphorus in various forms has been used with increasing frequency in recent years as a major constituent of flame retardant formulations while phosphate salts, in powder form, have found commercial application as fire extinguishants ${ }^{1-5}$. In particular, phosphorus additives have proven useful in commercial and developmental flame resistant treatments for thermoplastics. The need for these treatments to endure water exposure and melt processing has provided an impetus to the development of novel durable organo-phosphorus compounds which lend themselves to chemical bonding or to in situ polymerization with the thermoplastic substrate.

As recently as 1972, bulk synthetic fibers, including polyesters, acrylics and nylons, were stated as lacking an entirely satisfactory commercial process for flame retardation ${ }^{6}$. However, more recently, many processes have been claimed for the flame retardance of the popular synthetic fibers of polyester and blends of polyester, involving the incorporation of organo-phosphorus compounds ${ }^{7-10}$. The annual production of polyester is estimated to be in excess of a billion kilograms, much of this going into the fabrication of children's garments and other apparel. Approximately twenty percent of the burn injuries and up to fifty percent of the fire-related deaths in the United States may be related to flammable fabrics ${ }^{11}$. Obviously, an optimization of the flame retardant efficiencies of organo-phosphorus or competitive compounds would contribute to an alleviacion of the underlying hazard. 
A rational approach to the optimum use of phosphorus as a flame retardant requires an understanding of the chemical mechanism(s) by which flame retardancy is effected. However, despite extensive research and development on the use of phosphorus as a flame retardant, little is known about the retardancy mechanisms $1,7,8,10,11$. It appears that the main retardancy action of phosphorus may occur either in the condensed ${ }^{12-14}$ or the vapor phase $10,15,16$--depending somewhat on the polymer type. For the particular case of treated polyester/cellulosic fiber blends, it appears that the phosphorus retardant acts simultaneously both in the condensed and vapor phase for the cotton and polyester components, respectively ${ }^{17}$. A multiphase mechanistic action is also likely in flexible polyurethane foam systems ${ }^{18}$. For the few cases where chemical analyses have been performed on the char or substrate-residue following a flaming test on a synthetic polymer, it has been found that a major fraction of the phosphorus additive was lost to the vapor phase.

In view of the apparently diverse action of phosphorus in its mechanistic action in flame retardancy, we have selected for study a system where--by all available macroscopic criteria including oxygen index and thermal analyses--a vapor phase mode of inhibition is believed to be operating ${ }^{10}$. This system involves triphenylphosphine-oxide (TPPO) as a retardant for the polyester poly (ethyleneterephthalate) (PET), the flame retardancy effectiveness of which is well established $5,8,10$. Our primary objective, then, is to establish whether the flame retardancy observed for this system can be explained solely in terms of a vapor phase mechanistic action involving volatile phosphorus-containing species. Also, from the mechanistic model developed, can we expect phosphorus based retardants to be generally effective as vapor phase active flame retardants? An affirmative conclusion would require revision of the current seminal viewpoint to the effect that--"phosphorus is believed to perform most of its flame retardant function in the condensed phase" ${ }^{3}$; or alternatively, for halogen containing systems, that phosphorus merely serves as a carrier for a flame inhibiting halogen component ${ }^{1,18}$. 
The present study combines observations on:

- pyrolysis of polyester (PET) systems incorporating TPPO or similar P-additives.

- vaporization of pure flame retardant additives, and

- the effects of P-containing additives on the propagation of atmospheric pressure conical or flat laminar premixed flames.

These observations provide the basic chemical kinetic, thermodynamic, and gas-dynamic information necessary to the development of a mechanistic model for phosphorus-based flame retardant action in the gas phase. The experimental techniques of mass and optical spectrometry have been employed for the molecular characterization of pyrolyzing systems and for the kinetic and molecular characterization of inhibited flames.

\section{APPARATUS AND GENERAL PROCEDURES}

\subsection{Substrate Pyrolysis Studies}

The substrate-system pyrolysis studies are conveniently made using an established Knudsen effusion mass spectrometric technique, as described in greater detail elsewhere 19,20 . The basic relation of this technique is given by,

$$
\mathrm{p}=\mathrm{kIT},
$$

where $\mathrm{p}$ is the species partial pressure, I the species mass spectral positive ion intensity, T the sample temperature, and $k$ an instrument sensitivity constant. Usually $\mathrm{k}$ is obtained by vaporizing a known weight of sample, for a given vaporization area, time, temperature, and ion intensity ${ }^{19}$. With this approach we are able to monitor, under welldefined conditions, the individual vapor species and their partial pressures as a function of temperature, time, and both substrate and atmospheric composition.

In order to maintain free molecular effusion conditions it is necessary, in practice, to limit the total pressure in the knudsen cell to about $10^{-4} \mathrm{~atm}$. A lower pressure limit of about $10^{-12} \mathrm{~atm}$ is set by 
the sensitivity of the mass spectrometer. Hence an exceptionally wide pressure range is available with such a system. Even though the actual atmospheric pressure condition of a "real-fire" pyrolysis is not attained, the high sensitivity and wide dynamic pressure range allow the pertinent chemical reactions to be monitored. Thus we can simulate the probable "real-fire" pyrolysis chemistry and establish the likely flux of retardant to a flame front. In constrast to the results of commonly used thermogravimetric analyses, the mass spectrometric technique establishes the actual molecular identity of the retardant species as it enters the vapor phase and flame system.

During the thermal degradation or pyrolysis of a polymer-retardant mixture, such as PET-TPPO, the substrate composition may vary with time and temperature due to the differing volatilities of the individual components. For PET-TPPO mixtures at temperatures of less than about $400^{\circ} \mathrm{C}$, TPPO is the major volatile component and the substrate mole fraction of TPPO therefore decreases with the pyrolysis time. As will become evident in later discussion, it is possible to selectively vaporize all of the TPPO-component from the mixture.

In order to resolve the dependent effects of composition and temperature change we effectively monitor both the substrate composition and temperature as a function of pyrolysis time. The composition, at any specified time, is determined as follows. From chemical analyses, the initial and final substrate compositions are established. Also, the initial and final weights of polymer sample are determined gravimetrically. For a typical pyrolysis experiment, the polymer-retardant mixture is heated at a constant rate until the retardant component is completely lost by vaporization. The mass spectrometer monitors this release of retardant as a function of time and temperature. Pyrolysis of the polymer component is also monitored, though this is only significant when relatively high temperatures are reached $\left(>400^{\circ} \mathrm{C}\right)$. In most instances, the weight change found at the completion of the pyrolysis run corresponds to the known mass of retardant initially present. 
For these cases, the sensitivity factor $k$ can be determined from the known rate of weight-loss for TPPO and the measured positive ion intensity for the parent ion $(\phi)_{3} \mathrm{PO}^{+}$. This ion intensity constitutes more than $90 \%$ of the total ion signal for the TPPO species. During the pyrolysis procedure, measurement of the species partial pressures serves to define the substrate composition at any stage, since the weight loss of TPPO is related to its partial pressure $p$ and the duration of vaporization by the relation

$$
J=p /\left[2.2557 \times 10^{-2}(T / M)^{1 / 2}\right],
$$

where the flux $J$ is in units of $\mathrm{gm} / \mathrm{cm}^{2}-\mathrm{sec}, \mathrm{P}$ in atm, $\mathrm{T}$ in $\mathrm{K}$ and $\mathrm{M}$ the gm molecular weight (of TPPO in this case). The vaporization area in this case is given simply by the area of the knudsen effusion orifice which is $7.75 \times 10^{-3} \mathrm{~cm}^{2}$ for our system.

As the partial pressure $p$ and retardant mole fraction $x$ are therefore defined at various temperatures then the retardant activity coefficient $Y$ may be derived from the relation

$$
\gamma=p / p^{\circ} x,
$$

where $\mathrm{p}^{\circ}$ is the vapor pressure of pure retardant--as obtained from a separate vaporization experiment. A knowledge of $\gamma$ at various $T$ serves to define the thermodynamic character of the retardant-polymer mixture which is in a liquid state for most of the thermal regime of interest. This concept of a retardant activity coefficient assumes that thermodynamic equilibrium is established between TPPO vapor and the PET-TPPO substrate.

\subsection{Mass Spectrometric Analysis of Flames}

For the analysis of flames and flame inhibition phenomena we utilize a combination of mass and optical spectroscopic techniques which are complementary in their capabilities ${ }^{23}$. Details of the mass spectrometric system, and its application to flame analysis, have appeared elsewhere $21-23$. Basically, the technique involves the extraction of a 
molecular beam sample from a defined location in an atmospheric pressure flame followed by mass analysis of the beam components. Hence, profiles of species concentration versus distance along the flame axis may be determined.

\subsection{Optical Spectroscopic Analysis of Flames}

While the mass spectrometric technique can provide data on radical species flame profiles, the determination of H-atom profiles is more conveniently and accurately made using established optical spectroscopic procedures $23-25$. A schematic of our basic optical spectroscopic apparatus is given in Figure 1. This experimental arrangement is similar to that used by other workers for the measurement of emission line intensities in flames. A quartz lens and two apertures were used to extract and focus an optical image from the center of the inner flame at the entrance slit ( $150 \mu \mathrm{m}$ ) of a quarter meter monochromator (see Figure 1). The chopping wheel allows for beam modulation and phase sensitive detection techniques to be used--providing greater sensitivity for weak signals.

The burner used is of a modified sugden-type ${ }^{26}$. The outer flame compartment was constructed from brass with 1-mm holes to supply the premixed gases to the flame. The inner flame compartment was constructed from a silver soldered bundle of stainless steel hypodermic tubing. This arrangement provides a well-shielded virtually flat flame. The burner system is mounted on a motor driven kinematic table. This allows any part of the flame to be focused onto the monochromator entrance slit for the determination of intensity versus distance profiles.

For the determination of H-atom concentrations we utilize the established Li-technique ${ }^{25}$. This is an indirect method based on the balanced flame reaction,

$$
\mathrm{Li}+\mathrm{H}_{2} \mathrm{O}=\mathrm{LiOH}+\mathrm{H} \text {. }
$$

A weak solution of $\mathrm{Li}$ and $\mathrm{Na}$ salts ( 0.1 molar) is nebulized into the flame using a pneumatic type device driven by the nitrogen gas supply. 
Sodium does not undergo a hydroxide forming reaction and is present as Na atoms. Comparison of the resonance emission intensities for Li and $\mathrm{Na}$ then allows us to determine the concentration ratio of $\mathrm{Li}$ to $\mathrm{LiOH}$. Since the $\mathrm{H}_{2} \mathrm{O}$ concentration and equilibrium constant values for the above reaction are known for any given flame temperature, the concentration of hydrogen atoms can be deduced. The effect of flame retardant additives on the concentration of $\mathrm{H}$-atoms is used as a basis for our mechanistic arguments presented later. These additives are introduced to the flames by transpiration of the vapor (in the sample holder--see Figure 1) with the combustion gases.

\section{EXPERIMENTAL RESULTS AND DISCUSSION}

\subsection{Substrate Degradation Studies}

\section{a. Vaporization of Pure Retardants}

Preliminary to pyrolysis studies of polyester (PET) systems incorporating phosphorus retardant additives, it is necessary to obtain vapor pressure data for the pure retardants. For the phosphorus compounds of interest little or no vapor pressure data are available in the literature. Given the vapor pressure of pure retardant and its partial pressure over a PET-retardant mixture of known composition, we can derive thermodynamic activity coefficient and related data--as was indicated earlier. The retardants of interest here include triphenylphosphine oxide (TPPO) $\left(\mathrm{C}_{6} \mathrm{H}_{5}\right){ }_{3}$ PO, diphenylphenylphosphonate (DPPP) - $\left(\mathrm{C}_{6} \mathrm{H}_{5} \mathrm{O}\right)_{2}\left(\mathrm{C}_{6} \mathrm{H}_{5}\right)$ PO and the Lewis acid-base complex of $\left[\left(\mathrm{TPPO}_{2} \mathrm{SnCl}_{4}\right]\right.$.

Figure 2 shows the measured vapor pressures of TPPO and DPPP as a function of temperature together with the limited data of parts ${ }^{27}$ for comparison. The vaporization of TPPO from the [(TPPO) ${ }_{2} \mathrm{SnCl}_{4}$ ] complex as a function of temperature is given in Figure 3. The vapor phase composition above this compound was found to be particularly complex. In addition to TPPO and $\mathrm{SnCl}_{4}$ as major species, $\mathrm{SnCl}_{2}, \mathrm{HCl}$ and decomposition products of TPPO itself were also observed--particularly at temperatures of greater than $225^{\circ} \mathrm{C}$. This complexity of vaporization should not greatly 
affect the overall degree of retardancy as the $\mathrm{P}, \mathrm{Sn}$ and $\mathrm{Cl}$ components are all eventually lost to the vapor phase, $i . e$, no solid or char remained after pyrolysis of the [(TPPO $\left.2_{2} \mathrm{SnCl}_{4}\right]$ complex.

The vapor pressure data of Parts ${ }^{27}$, given in Figure 2, were obtained by a static method which ensures thermodynamic equilibrium for systems that maintain their molecular integrity on vaporization, such as TPPO and DPPP. That these data agree with the dynamic knudsen effusion data suggests the establishment of thermodynamic equilibrium in the Knudsen experiments.

\section{b. Polyester Substrate Degradation Studies}

The poly (ethyleneterephthalate) substrate systems considered in this work are indicated in Table I. These samples were in the form of a woven fabric with the phosphorus inhibitor compounds added to the polymer melt prior to extrusion. As TPPO has a relatively high thermal stability it is not likely to decompose during the spinning process ${ }^{28}$. Our mass spectrometric observations of TPPO as the only P-containing species released during pyrolysis of the PET samples verify this claim.

Pyrolysis studies of these samples were carried out under vacuum conditions using the Knudsen reactor technique. The rate of release of the phosphorus bearing species from the polymer was determined as a function of the dependent variables of temperature, time and composition. Figures 4-7 summarize the experimental results. Note that the retardant additive, TPPO or DPPP, is quantitatively released from the polymer to the vapor without decomposition for these low pressure conditions. Also, for conditions of low or medium heating rate, the measured total weight change corresponds to the amount of TPPO initially present in the mixture. That is, a negligible decomposition of PET resulted for these particular conditions.

A separate pyrolysis experiment was made under ambient atmospheric conditions to ascertain the gross features of the release of TPPO under "real-fire" conditions. This involved pyrolysis of the fabric sample 
Table I

Poly (ethyleneterephthalate) (PET) - Retardant Mixtures Considered

\begin{tabular}{clc}
\hline Sample & Composition $^{\mathrm{a}}$ & \% -Phosphorus \\
\hline A & PET+1\% TPPOb & 0.12 \\
B & PET+1\% TPPO+1\% Ny-6 & 0.11 \\
C & PET+4\% TPPO & 0.43 \\
D & PET+4\% TPPO+4\% Ny-6 & 0.40 \\
E & PET+6\% DPPP & 0.55 \\
\hline
\end{tabular}

aTPPO-containing samples were kindly supplied by R. H. Barker, Clemson University and flammability and other tests have been reported on by Bostic and Barker10,16 for these samples. Nominal composition is expressed in mole $\%$ relative to $\sim(\mathrm{CO}) \mathrm{C}_{6} \mathrm{H}_{4}(\mathrm{CO}) \mathrm{OCH}_{2} \mathrm{CH}_{2}$ On as the repeating unit of pET.

$b_{\text {Triphenylphosphine oxide }}$

c Nylon-6

$\mathrm{d}_{\text {Diphenylphenylphosphonate }}$

ecomposition as determined by actual elemental analysis of the prepared substrate. 
by a focused $\mathrm{CW}-\mathrm{CO}_{2}$ laser beam and the simultaneous sampling, at about $0.1 \mathrm{~cm}$ from the surface, of the vapor into the high pressure sampling mass spectrometer. Both TPPO and $\mathrm{CH}_{3} \mathrm{CHO}$ were identified as major pyrolysis products with very little atmospheric oxygen being detected at the sampling location.

It is well known that certain organic phosphorus retardants, including TPPO, are volatized during polymer processing at temperatures in excess of $200^{\circ} \mathrm{C}, e . g \cdot$, see Kushlefsky ${ }^{29}$. This loss leads to an inefficient utilization of the retardant additive. The vaporization curves of Figures 4-7 provide a quantitative measure of this effect. Note in the Figures 4-6 the comparative effect of a small amount of nylon- 6 on the release of TPPO from the polymer substrate to the vapor phase. These data indicate that the effect of the nylon-6 addition is to provide an enhanced retention of TPPO in the substrate such that the retardant is released at relatively higher temperatures--approaching those at which polymer decompositions occurs, $i . e ., 400-450^{\circ} \mathrm{C}^{10}$. Similarly, from the vaporization curves shown in Figure 7, it is apparent that the DPPP retardant additive is also released at significantly higher temperatures than for the TPPO case. It is generally believed that for a vapor phase retardant to be effective, the retardant must be present as a vapor at about the same time as combustible fuel is being generated by polymer decomposition ${ }^{15}$. We should therefore expect systems containing TPPO in the presence of nylon-6, or alternatively DPPP, to be more effective vapor phase active flame retardants than those containing only TPPO as a retardant additive. This is known to be the case at least for the TPPOnylon-6 combination ${ }^{5}$.

Complexes of triphenylphosphine oxide with Lewis acids, such as $\mathrm{SnCl}_{4}$, are known to impart excellent flame retardant properties to a large variety of thermoplastic polymers including poly(ethyleneterephthalate) ${ }^{29}$. Moreover, their degree of effectiveness is greater than that of the pure phosphine oxide--particularly under conditions of long-term sample exposure to a flame. It is believed that the complexing reduces 
the tendency for the phosphine oxide to be vaporized prior to polymer thermal degradation. Our "observed" vaporization curves given in Figure 8 support this viewpoint, since the complex would require about a $70^{\circ} \mathrm{C}$ greater temperature than TPPO to achieve the same degree of volatilization from a PET substrate. Thus the early, and undesirable, release of some of the TPPO from PET substrates could be limited by the use of (TPPO) ${ }_{2} \cdot \mathrm{SnCl}_{4}$ rather than TPPO as the retardant additive. We surmise that the known ${ }^{8}$ synergistic effect of benzil, or related additives, may also be related to an enhanced retention of TPPO in the melt prior to polymer degradation.

\section{c. Activity Coefficients and Partial Pressures}

The individual vaporization curves of Figures 4-7 represent conditions of variable temperature and retardant mole fraction within the substrate. In order to show the effects of temperature and composition separately, we utilize the information provided by the use of different heating rates as follows. As shown by the comparison of curves in Figures 4 and 6 , a higher heating rate allows the partial pressure of TPPO to be determined at a higher temperature but at the same substrate composition. For instance, from Figures 6 and 4 for PET + 1\% TPPO the $75 \%$ weight loss (of TPPO), corresponding to X(TPPO) equal to 0.0025 mole fraction, occurs at $320^{\circ} \mathrm{C}$ and $220^{\circ} \mathrm{C}$ for the fast and slow heating rates, respectively. Hence, the activity coefficients $\gamma$ at these temperatures are given as

$$
\gamma_{320^{\circ}}=\mathrm{p} / \mathrm{P}^{\circ} \mathrm{X}(\mathrm{TPPO})=0.05 \text { and } \gamma_{220^{\circ}}=3.5 \text {. }
$$

Clearly, $\gamma$ is very temperature dependent for fixed X(TPPO). For the case where $T=220^{\circ} \mathrm{C}$ and $X(T P P O)=0.005, \gamma_{220^{\circ}}=3.1$. Hence, $\gamma$ is relatively insensitive to composition for these relatively dilute mixtures. Activity coefficient data, derived in this manner, are summarized in Figure 9 where a reasonably linear dependence of $\log \gamma$ on $T$ is indicated, as would be expected for a solution at thermodynamic equilibrium. The slope of this curve (see Figure 9) is in fact a measure of the excess partial molar heat of vaporization of TPPO from the PET-TPPO solution. 
The main uncertainty in $\gamma$ arises from the fact that two pressure, and hence $k$, determinations are needed for its calculation. We estimate an uncertainty of a factor of two for $\gamma$. This uncertainty is reflected by the scatter of data given in Figure 9.

From the general $\gamma$-T relationship as given in Figure 9, we can express the partial pressure of TPPO, above various PET-TPPO substrates, as a separate function of substrate TPPO mole fraction and temperature as shown in Figure 10. The upper solid curve at $450^{\circ} \mathrm{C}$ was constructed from the established $\gamma$ value at 0.0075 nole fraction TPPO with the assumption that

$$
\gamma \quad \alpha \quad x
$$

over the range $\mathrm{x}=0.0075-1.0$ and the relation,

$$
p=p^{\circ} \gamma X
$$

By definition,

$$
\gamma=1 \text { for } x=1
$$

and the small $\gamma_{450^{\circ} \mathrm{C}}$ value must necessarily increase with $\mathrm{X}$ for TPPO concentrations greater than those studied here. The lower solid curve of Figure 10 assumes $\gamma$ independent of $x$, which is only likely to be valid for small values of $\mathrm{x}$.

That $\gamma$ has values of greater than unity for relatively low temperature conditions (see Figure 9) is indicative of a low degree of binding in the polymer solution as compared with the standard state crystalline form of TPPO. However, the rapid decrease in $\gamma$ with increasing temperature indicates an enhanced chemical binding of TPPO by the polymer with increased temperature. Perhaps at low temperatures, i.e., less than $200^{\circ} \mathrm{C}$, TPPO is present as aggregates-(TPPO) ${ }_{n}$; but at higher temperatures these oligomers dissociate and the monomers become more dispersed in the solvent, and are, in fact, chemically bound by the PET.

\subsection{Mass Spectrometric Analysis of Flame Species}

As triphenylphosphine oxide is a combustible species, it is not 
likely to be stable in the hotter flame region and therefore should not significantly enter into cyclic reactions involving flame radicals. Hence, its products of decomposition are the most likely candidates for participation in inhibition reactions leading to the loss of flame radicals.

Figure 11 shows the decomposition of TPPO in the preflame region (i.e., negative distances relative to $z$ ) of a fuel rich $\mathrm{CH}_{4} / \mathrm{O}_{4} / \mathrm{Ar}$ flame with the production of PO as a significant species in the region of the flame reaction zone. In $\mathrm{H}_{2} / \mathrm{O}_{2} / \mathrm{N}_{2}$ flames, an additional species $\mathrm{PN}$ was observed. Typical species concentration data resulting from the addition of trimethylphosphate (TMP) to a $\mathrm{H}_{2} / \mathrm{O}_{2} / \mathrm{N}_{2}$ flame of molar composition given by the ratios $3.1 / 1 / 4.0$ are:

$$
\mathrm{PO}(20), \mathrm{PN}(1.5), \mathrm{HPO}_{2}(0.4) \text { and } \mathrm{PO}_{2}, \mathrm{P}_{2}, \mathrm{HPO}(20.05) \text {, }
$$

where the partial pressures in units of $10^{-4}$ atm are given in the parentheses. These measurements refer to a flame location equivalent to 1 ms time downstream from the reaction zone in a premixed conical flame.

Note that PO is generally the most significant species in these and other flames considered. The species concentrations were calculated from the mass spectral relative ion intensities and the known total concentration of P-additive entering the flame--as determined by the known vapor pressure of TPPO or TMP at the sample holder temperature. In order to obtain data in the pre-flame region, the mass spectrometric measurements were made using conical flames which are more accessible to probing of the pre-flame region than the flat flames used for optical spectroscopic studies.

\subsection{Optical Spectroscopic Analysis of Flame Species}

Established optical spectroscopic techniques have been utilized in the present work for monitoring the species $\mathrm{H}, \mathrm{PO}$ and/Or HPO in premixed flat $\mathrm{H}_{2} / \mathrm{O}_{2} / \mathrm{N}_{2}$ flames. In this work, although the relative values of the H-atom concentration [H] could be followed using the resonance emission 
intensity of $\mathrm{CuH}$, as described by other workers ${ }^{24}$, it was found that better reproducibility of data could be obtained using the comparative Li/LiOH procedure mentioned earlier. Usually, the phosphorus-containing additive was introduced only into the central flame of the burner system. This was permissable since concentration diffusion effects between the shield and central flames--resulting from a phosphorus induced depletion of radicals in the inner flame--were found to be negligible.

Two $\mathrm{H}_{2} / \mathrm{O}_{2} / \mathrm{N}_{2}$ flames, with compositions defined by the mole ratios $3.7 / 1 / 3$ and $3.7 / 1 / 2.2$, were investigated. Flame temperatures were found to be $1900 \mathrm{~K}$ and $1980 \pm 50 \mathrm{~K}$, respectively, using the sodium-doublet line reversal technique. These flame temperatures are well below the adiabatic values due to heat loss effects to the brass and steel watercooled burner. The resultant H-atom concentration levels were found to compare reasonably well with those reported in the literature for similar $\mathrm{H}_{2}$-fueled flames. In fact, the $\mathrm{H}$-atom versus time-from-reactionzone profiles were found to be consistent with existing kinetic data for the post flame recombination processes.

When using the flat flame burner it was difficult to control the concentration of TPPO reaching the flame on account of the elevated temperature needed to maintain a suitable vapor pressure. Hence, the more volatile additives of trimethylphosphate (TMP) - $\left(\mathrm{CH}_{3} \mathrm{O}\right)_{3} \mathrm{PO}$ and $\mathrm{POCl}_{3}$ were used in this case. Mass spectrometric experiments in conical flames verified a similar decomposition and species production character for TMP and TPPO. The effect of the separate addition of TMP and $\mathrm{POCl}_{3}$ on the H-atom concentration profile for the cooler $\mathrm{H}_{2} / \mathrm{O}_{2} / \mathrm{N}_{2}$ flame are shown in Figure 12. Corollary experiments were performed with small additions of methane gas to determine the possible reduction in $\mathrm{H}$-atom concentration due to the hydrocarbon content of TMP. This hydrocarbon inhibitor effect was found to account for only about $8 \%$ of the total reduction by TMP and this small correction has been applied to all of the H-atom concentration data for TMP additions.

Two resonance emission lines at 525 and $554 \mathrm{~nm}$, which have been 
attributed in the literature to HPO, were also monitored 30,31 . Their emission intensity flame profiles, for various amounts of TMP, are shown in Figure 13 for the two flame systems. As may be deduced from the data given in the Figure 13, these emission intensities show an approximate linear variation with increasing TMP concentration for a fixed flame location at burner distances of greater than about $1 \mathrm{~cm}$.

\section{MECHANISM OF FLAME RETARDANCY}

\subsection{Mass Transport of Retardant to Flame Front}

Under conditions of actual flame spread across a polymer substrate, the retardant and fuel are not necessarily released in proportion to their initial mole fractions. For instance, Volans showed that the concentration of released $\mathrm{HBr}$, relative to fuel, could be as high as $21 \%$ even though the substrate fraction was equivalent to only $2 \% \mathrm{HBr}^{32}$. We consider that the actual flame concentration of inhibitor species under "real-fire" conditions is determined by the local inhibitor concentration at the substrate surface and the mass flux of inhibitor through a boundary layer ${ }^{19}$. The boundary layer, located between the substrate surface and the bulk gas or flame, impedes the diffusional transport of retardant species to the flame and it is necessary to consider whether sufficient retardant will reach the flame to effect inhibition. The boundary layer concept and its effect on retardant species concentration is indicated schematically in Figure 14.

From the observed amount of TMP needed to cause dramatic reductions in $\mathrm{H}$-atom concentrations and burning velocities for $\mathrm{H}_{2}$-fueled flames, a sufficient partial pressure of inhibitor in the flame would be about $10^{-3} \mathrm{~atm}$. However, we should keep in mind that hydrocarbon flames, which are inherently weaker and contain far fewer $\mathrm{H}$-atoms than $\mathrm{H}_{2}$-fueled flames ${ }^{33}$, require correspondingly smaller amounts of inhibitor for retardation. Hence, even inhibitor pressures of less than $10^{-3}$ atm should suffice for the suppression of a flame supported by polyester pyrolysis. Consider the partial pressure of retardant at the substrate surface 
needed to maintain about a $10^{-3}$ atm pressure of retardant at the flame front. The relationship between surface partial pressure Ps and mass flux $J$, in the presence of a boundary layer of thickness $\delta$, is given by:

$$
J(T P P O)=(D M / \delta R T)[P S-P b] g / \mathrm{cm}^{2}-s e c,
$$

where $\mathrm{Pb}$ is the partial pressure of TPPO in the bulk gas or pre-flame region, $D$ the diffusion coefficient (of TPPO) in the gas medium, $M$ the gram molecular weight (of TPPO), $R$ the gas constant and $T$ the absolute temperature $(K)$. From our mass spectrometric observation of TPPOdepletion in the pre-flame region of premixed flames (e.g., see Figure 11) we can assume $\mathrm{Pb}$ to be negligible, i.e., the flame serves as a sink for TPPO. The boundary layer thickness for a typical bulk gas velocity of $10 \mathrm{~cm} / \mathrm{sec}$ has been previously estimated to be

$$
\delta=0.2 \mathrm{~cm},
$$

see Hastie and McBee ${ }^{19}$. A value of $D$ can be calculated from hard sphere gas kinetic theory. For an estimated TPPO collision diameter of $10 \AA$ we calculate,

$$
D=0.19 \mathrm{~cm}^{2} \mathrm{sec}^{-1} \text { at } 450^{\circ} \mathrm{C} \text {. }
$$

Therefore, for an assumed Ps of $10^{-2} \mathrm{~atm}$, the flux is

$$
\begin{aligned}
J(T P P O) & =3.71 \times 10^{-5} \mathrm{~g} / \mathrm{cm}^{2} \mathrm{sec} \\
& =1.29 \times 10^{-7} \mathrm{~mol} / \mathrm{cm}^{2} \text { sec at } 450^{\circ} \mathrm{C} .
\end{aligned}
$$

To determine the flame concentration resulting from this flux consider the corresponding fuel flux. For the case of PET pyrolysis we know that $\mathrm{CH}_{3} \mathrm{CHO}$ is the predominant fuel component. Under the stoichiometric combustion condition of

$$
\mathrm{CH}_{3} \mathrm{CHO}+5 / 2 \mathrm{O}_{2}=2 \mathrm{CO}_{2}+2 \mathrm{H}_{2} \mathrm{O},
$$

the major flame component is $\mathrm{N}_{2}$ (0.725 mole fraction). A high $\mathrm{N}_{2}$ concentration can also be expected at the substrate surface. If we assume this to be $0.725 \mathrm{~atm}$ then the maximum fuel concentration at the surface is $0.275 \mathrm{~atm}$ and the fuel flux is calculated as: . 


$$
\mathrm{J}\left(\mathrm{CH}_{3} \mathrm{CHO}\right)=1.8 \times 10^{-5} \mathrm{~mol} / \mathrm{cm}^{2} \mathrm{sec} \text { at } 450^{\circ} \mathrm{C},
$$

where $\mathrm{D}\left(\mathrm{CH}_{3} \mathrm{CHO}\right)=1.0 \mathrm{~cm}^{2} \mathrm{sec}^{-1}$ (using an estimated collision cross section of $2.9 \AA)$. The relative molar flux of retardant to fuel is then

$$
J(T P P O) / J\left(\mathrm{CH}_{3} \mathrm{CHO}\right)=7 \times 10^{-3},
$$

and for a stoichiometric flame condition where 0.078 mole fraction of $\mathrm{CH}_{3} \mathrm{CHO}$ is required the corresponding TPPO concentration is calculated as

$$
\text { TPPO in flame }=5.5 \times 10^{-4} \mathrm{~atm} .
$$

This inhibitor pressure is of the correct order of magnitude for an effective degree of flame inhibition to occur. Hence, a substrate surface TPPO partial pressure of $10^{-2}$ atm should provide a suitably high flux of retardant to the flame. From the Figure 10 we find that P(TPPO) $=10^{-2}$ atm at $450^{\circ} \mathrm{C}$ for a substrate TPPO mole fraction of about 0.3 . Hence, as the initial concentration is typically only 0.01 TPPO mole fraction, a considerable preferential volatilization of PET is needed before the activity of TPPO is sufficient to generate the desired vapor concentration. However, this production of retardant vapor is most likely supplemented by the release of TPPO ahead of the flame front and prior to the polyester decomposition. For instance, from the partial pressure isotherms given in Figure 10, the partial pressure of TPPO at $200^{\circ} \mathrm{C}$ is greater than that at $450^{\circ} \mathrm{C}$ for small TPPO mole fraction and an accumulation of TPPO could occur at cool regions ahead of the flame front.

These estimates of retardant flux and flame species concentration are probably lower limit values. Under conditions of substantial polymer pyrolysis it is likely that the passage of fuel gas through the meltsurface will disturb the adjacent gas boundary layer and result in a lower value of $\delta$ than that estimated for the ideal quiescent-surface laminar flow condition.

4.2 Action of P-Containing Species in Flame Inhibition From the observed effect of phosphorus flame additions on the H-atom 
concentration profiles, the following mechanism for inhibition is suggested.

For conditions where the flame processes are determined mainly by the chain branching reaction

$$
\mathrm{H}+\mathrm{O}_{2} \rightarrow \mathrm{OH}+\mathrm{O},
$$

the burning velocity or flame speed can be expected to be proportional to the H-atom concentration - [H] as a first order approximation, e.g., see Fristrom and Sawyer ${ }^{34}$. This is demonstrated empirically in Figure 15 for the case of $\mathrm{CH}_{4}$ inhibition of a fuel $\mathrm{rich} \mathrm{H}_{2} / \mathrm{O}_{2} / \mathrm{N}_{2}$ flame. A similar correlation can be expected where phosphorus is the inhibitor. Hence, a 50\% reduction in $\mathrm{H}$-atom concentration, for example, is equivalent to a dramatic reduction in burning velocity (see Figure 15). From Figure 12 we find that only $5.7 \times 10^{-4}$ mole fraction $P$ (as TMP) is needed to achieve this degree of inhibition. As has been argued in more detail elsewhere, only a catalytic involvement of $\mathrm{P}$-species with the flame radicals can explain such a strong perturbation of the normal flame chemistry ${ }^{15}$. The catalytic processes must be more efficient than the normal radical depletion reactions of

$$
\begin{aligned}
& \mathrm{H}+\mathrm{OH}+\mathrm{X} \rightarrow \mathrm{H}_{2} \mathrm{O}+\mathrm{X} \text { ( } \mathrm{X} \text { is a third body, e.g., } \mathrm{H}_{2} \mathrm{O}, \mathrm{N}_{2} \text { ) } \\
& \mathrm{H}+\mathrm{H}+\mathrm{X} \rightarrow \mathrm{H}_{2}+\mathrm{X}
\end{aligned}
$$

which govern the loss of H-atoms in the post flame region. From the known rates of these processes it can be shown that times of several milliseconds, relative to the reaction zone, are required for these recombinations to reduce the radical concentrations to the thermodynamic equilibrium levels--see also Figure 12. This recombination time is effectively reduced by the presence of inhibitors such as $\mathrm{P}, \mathrm{NO}, \mathrm{SO}_{2}$ ' $\mathrm{Sn}, \mathrm{Ba}$ and other metals ${ }^{36-40}$. Apparently, species such as $\mathrm{NO}, \mathrm{SO}_{2}$ ' $\mathrm{SnO}$, or $\mathrm{BaOH}$, denoted below as $\mathrm{M}$, are involved in a catalytic scheme where the rate determining step

$$
\mathrm{H}+\mathrm{M}(+\mathrm{X}) \rightarrow \mathrm{HM}(+\mathrm{X})
$$


is many orders of magnitude faster than the normal H-atom recombination processes. We suggest that PO is involved in an analogous process which is essentially the fundamental basis of phosphorus-induced flame retardancy. Then the kinetically important reactions would be

$$
\begin{aligned}
& \mathrm{PO}+\mathrm{H}(+\mathrm{X}) \rightarrow \mathrm{HPO} \text { or } \mathrm{POH}(+\mathrm{X}) \\
& \mathrm{HPO}(\text { or } \mathrm{POH})+\mathrm{H} \rightarrow \mathrm{H}_{2}+\mathrm{PO} .
\end{aligned}
$$

Further studies are in progress to establish this reaction scheme for phosphorus inhibited flames.

The slopes of $[\mathrm{H}]^{-1}$ versus time plots in the presence of the catalyst provide a kinetic measure of the effectiveness of the catalytic process. Figure 16 shows such plots for TMP and the similar $\mathrm{SO}_{2}$ data of Kallend 37 for comparison. The catalytic efficiency or figure of merit for an inhibitor, at a given concentration, has been proposed as the ratio of such a slope relative to that for the uninhibited flame. Table II lists the derived catalytic efficiencies for several flames, together with the $\mathrm{SO}_{2}$ comparison data.

The emission intensity profiles for the HPO species also reflect the presence of radical recombination processes involving this species (see Figure 13). Schemes such as

$$
\begin{aligned}
& \mathrm{PO}+\mathrm{H}(+\mathrm{X}) \rightarrow \mathrm{HPO} *(+\mathrm{X}) \\
& \mathrm{PO}+\mathrm{H}_{2}+\mathrm{OH} \rightarrow \mathrm{HPO} *+\mathrm{H}_{2} \mathrm{O}
\end{aligned}
$$

have been suggested as the source of the observed chemiluminescence 30,41 . Reactions such as these could explain the initial sharp decrease in emission intensity downstream from the reaction zone since the H-atom concentration profiles show a similarly sharp decrease for the same flame location. At distances of greater than about $1 \mathrm{~cm}$, where the intensities show an increase, it is likely that additional Po or excited HPO is formed due to the temperature reduction and air entrainment that occurs with increasing distance from the reaction zone. However, insufficient thermochemical data is presently available to allow a quantitative 
Table II

Catalytic Efficiencies for Phosphorus (in comparison with $\mathrm{SO}_{2}$ ) as a Flame Inhibitor

\begin{tabular}{|c|c|c|c|c|c|}
\hline $\begin{array}{l}\text { Flame } \\
\left(\mathrm{H}_{2} / \mathrm{O}_{2} / \mathrm{N}_{2}\right)\end{array}$ & $\begin{array}{l}\text { Temperature } \\
\mathrm{K}\end{array}$ & Additive & Mole : & $\begin{array}{c}{[\mathrm{P}]} \\
\text { (mole fraction) }\end{array}$ & $\begin{array}{l}\text { Cataly } \\
\text { Effici }\end{array}$ \\
\hline $3.7 / 1 / 3$ & 1930 & TMP & 0.26 & $5.7 \times 10^{-4}$ & 1.7 \\
\hline $3.7 / 1 / 3$ & 1900 & $\mathrm{POCl}_{3}$ & 0.7 & $1.4 \times 10^{-4}$ & 1. \\
\hline $3.7 / 1 / 2.2$ & 1980 & TMP & 0.3 & $6.7 \times 10^{-4}$ & \\
\hline $3 / 1 / 4$ & 2115 & $\mathrm{so}_{2}^{\mathrm{a}}$ & 0.36 & $1.8 \times 10^{-3}$ (S) & 1. \\
\hline $3 / 1 / 4$ & 2115 & $\mathrm{SO}_{2}$ & 0.71 & $3.5 \times 10^{-3}$ (S) & \\
\hline
\end{tabular}

$\mathrm{a}_{\text {The }} \mathrm{SO}_{2}$ data is from Kallend ${ }^{37}$.

$\mathrm{b}_{\mathrm{An}}$ inactive additive would yield a value of 1.0 . 
analysis of these species profiles.

\section{CONCLUSIONS}

We find that the TPPO or DPPP retardant additives can be quantitatively released to the vapor phase from poly(ethyleneterephthalate) substrates. However, the rate of release to the flame is strongly influenced by chemical thermodynamic and gas-dynamic factors such as

- the substrate temperature,

- the chemical form of the retardant additive, $i . e$, whether the

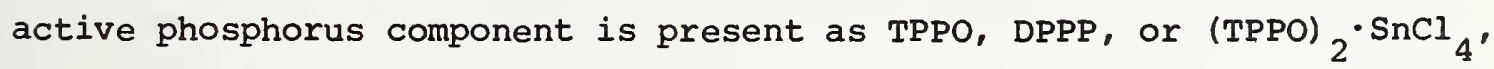

- the synergistic presence of small amounts of nylon- 6 in the substrate,

- the formation of a gas boundary layer at the polymer-preflame gas interface, and

- the molecular weight and size of the vaporized retardant species, which affect the diffusive flux through the boundary layer.

Consideration of the combined effect of these mass transport determining factors, for likely flame spread conditions, indicates that the flux of retardant to the flame front will be reduced by 3 to 5 orders of magnitude over that allowed by an ideal system--in the thermodynamic sense. Even so, the amount of inhibitor species reaching the flame reaction zone is shown to be ample for a dramatic reduction in flame strength to occur. A concentration of several hundred ppm-phosphorus in the flame is sufficient to markedly reduce the H-atom population and concomitantly the burning velocity or flame strength.

The observed degree of flame retardancy imparted by TPPO to PET substrates can be adequately accounted for by a vapor phase mode of flame inhibition--without recourse to arguments concerning modification of the polymer physicochemical pyrolysis properties. This argument is consistent with an earlier observation that the presence of TPPO did not affect the nature of PET decomposition 10,16. For substrate systems with suitable activity coefficient characteristics, of the type indicated here, 
we can expect the observed vapor-phase mode of flame retardancy to be generally effective. Given this basic requirement, this type of inhibition should provide a viable means of producing less flammable bulk synthetic fibers and polymer substrates in general.

In conclusion, it is pertinent to note that the demonstrated flame inhibiting action of phosphorus, in the absence of a halogen source, now provides some insight as to the mechanism for the so-called synergism found for phosphorus-halogen retardant formulations. 


\section{REFERENCES}

+ Present address, Science Policy Division, Congressional Research Service, Library of Congress, Washington, D. C. 20540

1. Lyons, J. W., (1970) J. Fire and Flammability, 1,302.

2. Kuryla, W. C. and Papa, A. J., Eds., Flame Retardancy of Polymeric Materials, Marcel Dekker, Inc., New York, (1973).

3. Hilado, C. J., Flammability Handbook for Plastics, 2nd Ed., Technomic Print Co., Westport, Conn. (1974).

4. Tesoro, G. C. and Meiser, C. H., Jr., (1970) Tex. Res. J., 40, 430 .

5. Gardner, J. H., U. S. Patent No. 3,629,365 (1971).

6. Collins, J. R. (1972), Plastics and Polymers, 40, 283; see also Baum, B. M. (1973), Chem. Tech. July, 416.

7. Bostic, J. E., Yeh, K. N. and Barker, R. H., (1973), J. Appl. Polymer Science, 17, 471 .

8. Juelke, C. V. and Trapasso, I. E., U. S. Patent No $3,681,281$ (1972).

9. Cleaver, R. F., (1973) Polymer, Paint and colour J., 107.

10. Bostic, J. E. and Barker, R. H., "Pyrolysis and Combustion of Polyester, Part II. Effect of Triphenylphosphine Oxide as a Flame Retardant", presented at a short course sponsored by the Plastics Institute of America at Clemson Univ., Clemson, S. C. (1974).

11. U. S. Dept. of Health, Education and Welfare, "Studies of Death, Injuries and Economic Losses Resulting from Accidental Burning of Products, Fabrics or Related Materials (Sept. 1965- Feb. 1969), First Report.

12. Vandersall, H. I., (1971) J. Fire and Flammability, 2, 97.

13. Hendrix, J. E., Bostic, J. E., Olson, E. S. and Barker, R. H., (1970), J. Appl. Polymer Sci., 14, 1701.

14. Drews, M. J. and Barker, R. H. (1973), Textilveredlung, $\underline{8}, 180$.

15. Hastie, J. W. (1973), J. Res. NBS, A. Physics and Chemistry, 77A, 733. 
16. Bostic, J. and Barker, R., Ph. D. Thesis of Bostic, Clemson Univ. (1972).

17. Penser, J. E., Sello, S. B., and Brenner, W. (1974), J. Fire and Flammability, $\underline{5}, 227$.

18. Benbow, A. W. and Cullis, S. F. (1975), Combust. Flame, 24, 217.

19. Hastie, J. W. and McBee, C. I. in "The Mechanisms of Halogenated Fire Suppressants", ACS Symposium Series, in press (1975).

20. Grimley, R. T., "Mass Spectrometry" in The Characterization of High Temperature Vapors, 195, Ed. J. I. Margrave, John Wiley and Sons, Inc., New York, (1967).

21. Hastie, J. W., (1973) Combust. Flame, 21, 49.

22. Hastie, J. W., (1973), Combust. Flame, 21, 187.

23. Hastie, J. W. (1975), Int. J. Mass Spec. Ion Physics, 16, 89.

24. Bulewicz, E. M. and Sugden, T. M. (1959), Trans. Faraday Soc., $\underline{52}, 1475$.

25. Bulewicz, E. M. , James, C. G. and Sugden, T. M. (1956), Proc. Roy. Soc. A255, 89.

26. Padley, P. J. and Sugden, T. M. (1959), 7th Intl. Symp. Combustion, Butterworths, London, 235.

27. Parts, L., Thermal Stability of Some Phosphorus-and HalogenContaining Fire Retardants, (1973), private communication.

28. Bailey, W. J., Muir, M. and Markesheffel, F., (1962), J. Org. Chem. 27, 4404 .

29. Kushlefsky, B. G., U. S. Patent No. 3,660,350 (1972).

30. Fenimore, C. P., and Jones, G. W., (1964), Combust. Flame 8 , 133.

31. Lam Than My and Peyron, cited in The Spectroscopy of Flames,

A. G. Gaydon, Chapman and Hall, London, (1974).

32. Volans, P., (1967), Trans.J. Plastics Inst. (Jan.), 47.

33. Fenimore, C. P., and Jones, G. W., (1958), J. Phys. Chem. 62, 693.

34. Fristrom, R. M. and Sawyer, R. F., Proc. AGARD Symp. Aircr. Fuels, Lubricants, Fire Safety, 37th, The Hague, (1971). 
35. Miller, D. R., Evers, R. L., and Skinner, G. B. (1963), Combust. Flame, ㄱ, 137 .

36. Cotton, D. H. and Jenkins, D. R. (1971), Trans. Faraday Soc., $67,730$.

37. Kallend, A. S. (1972) Combust. Flame, 227.

38. Fenimore, C. P. and Jones, G. W. (1964), Combust. Flame $\underline{8}, 133$.

39. Bulewicz, E. M. and Sugden. T. M. (1964), Proc. Roy. Soc. A277, 143.

40. Bulewicz, E. M. and Padley, P. J. (1971), 13th Intl. Symp. Combustion, 73 .

41. Gilbert, P. T., in Analytical Flame Spectroscopy, Ed.

R. Mavrodineanu, Springer-Verlag, New York, 238 (1970). 



\section{Figure Captions}

1. Schematic of the optical spectroscopic apparatus for the determination of species emission intensity flame profiles.

2. Vapor pressures of triphenylphosphine oxide-TPPO (open circles) and diphenylphenylphosphonate-DPPP (open squares) as a function of reciprocal temperature. The closed circle and square data for TPPO and DPPP, respectively, are from Parts (Ref. 27); the known melting points for both compounds are also indicated.

3. Partial pressures of TPPO (open circles) released during thermal degradation of the complex $\left[\mathrm{SnCl}_{4} \cdot 2 \mathrm{TPPO}\right]$; the vapor pressure curve of pure TPPO is also indicated for comparison.

4. Partial pressures of TPPO released during pyrolysis of the substrates $\mathrm{PET}+1 \% \mathrm{TPPO}$ (open circles) and PET + 1\% TPPO + 1\% NY-6 (closed circles); the numbers indicate successive weight-r losses of the TPPO additive. For this and subsequent similar data, the highest temperature point represents a virtually complete depletion of TPPO from the substrate, $i . e ., 100 \%$ weight loss of TPPO. The heating rate was maintained at $\sim_{1}{ }^{\circ} \mathrm{C} / \mathrm{min}$.

5. Partial pressures of TPPO released during pyrolysis of the substrates, PET + 18 TPPO (open circles) and PET + 18 TPPO + 1\% Ny-6 (closed circles) at a heating rate of $\varkappa_{4}^{\circ} \mathrm{C} / \mathrm{min}$.

6. Partial pressures of TPPO released during pyrolysis of the substrates $\mathrm{PET}+1 \%$ TPPO (open circles) and PET + 1\% TPPO + $1 \% \mathrm{NY}-6$ (closed (circles) at a heating rate of $\sim 8^{\circ} \mathrm{C} / \mathrm{min}$.

7. Partial pressures of TPPO released from the substrates PET +48 TPPO (open circles) and PET $+48 \mathrm{TPPO}+4 \% \mathrm{NY}-6$ (closed circles), shown in comparison with the partial pressures of DPPP over the substrate $\mathrm{PET}+6 \%$ DPPP (open squares); a heating rate of $\sim 4{ }^{\circ} \mathrm{C} / \mathrm{min}$. was used.

8. Comparison of the release of TPPO and DPPP from the various PET substrates given in Figure 7 and a hypothetical substrate of PET + 48 TPPO where TPPO is present as the complex $\left[\mathrm{SnCl}_{4} \cdot 2 \mathrm{TPPO}\right]$ and a unit activity coefficient for the complex in PET is assumed.

9. Activity coefficients of TPPO as a separate function of temperature and composition in the PET substrates considered in Figs. 4-7; the actual TPPO mole fraction compositions at the indicated temperatures are as follows:
0.0075 (closed circles);
$0.0075+0.01 \mathrm{Ny}-6$ (open circles);
0.005 (closed squares);
$0.005+0.01 \mathrm{Ny}-6$ (open squares);
0.0025 (open triangles); $0.0025+0.01 \mathrm{Ny}-6$ (closed triangles);
$0.004+0.04 \mathrm{Ny}-6$ (seminclosed circle). 
10. Isotherms of TPPO partial pressure versus TPPO mole fraction in PET, as calculated from the data of Figure 9. The upper curve at $450^{\circ} \mathrm{C}$ assumes $\gamma$ proportional to mole fraction $x$ and the lower curves assume $\gamma$ independent of $x$.

11. Relative concentration profiles for $\phi_{3} P O(i . e ., T P P O)$ and its decomposition products of $\mathrm{PO}$ and the $63 \pm 1$ a.m.u. grouping of $\mathrm{HPO}_{2}, \mathrm{PO}_{2}$ and $\mathrm{P}_{2}$ species. The position $\mathrm{z}$ represents the luminous reaction zone location in the conical flame of unburnt gas of molar composition $\mathrm{CH}_{4}(3.3) / \mathrm{O}_{2}(2.5) / \mathrm{Ar}(1.0)$.

12. H-atom concentration profiles as a function of time from the reaction zone of a $\mathrm{H}_{2} / \mathrm{O}_{2} / \mathrm{N}_{2}=3.7 / 1 / 3$ flame at $\mathrm{T} \sim 1900 \mathrm{~K}$, showing the effect of $5.7 \times 10^{-4}$ mole fraction $P$ as TMP (open circles) and $1.4 \times 10^{-4}$ mole fraction $\mathrm{P}$ as $\mathrm{POCl}_{3}$ (open squares) additions; note that $1 \mathrm{~ms}$ time corresponds to a distance of $1.8 \mathrm{~cm}$ in this flame.

13. Emission intensity versus distance-from-burner profiles for the discrete 525 and $554 \mathrm{~nm}$ spectral lines attributed to HPO; note that the reaction zone for these flames lies within $20.1 \mathrm{~cm}$ distance from the burner. For the curve sets (a) and (c) the mole fraction amounts of $\mathrm{P}$ present are $5.7 \times 10^{-4}$ (open squares), $9.5 \times 10^{-4}$ (open circles) and $2.1 \times 10^{-3}$ (closed circles), for sets (b) and (d) $-6.7 \times$ $10^{-4}$ (open squares), $1.1 \times 10^{-3}$ (open circles) and $2.5 \times 10^{-3}$ (closed circles). The flames used are given by the mole ratios, $\mathrm{H}_{2} / \mathrm{O}_{2} / \mathrm{N}_{2}=$ $3.7 / 1 / 3$ for sets (a) and (c) and $3.7 / 1 / 2.2$ for sets (b) and (d).

14. Schematic of an idealized flame-spread system showing the presence of a boundary layer between the substrate and flame and its qualitative effect on retardant $\left(\phi_{3} \mathrm{PO}\right)$ concentration; see the main text for an explanation of symbols.

15. Relationship between flame speed and H-atom concentration at the reaction zone for various amounts of $\mathrm{CH}_{4}$ (given in parentheses as mole-\% added) in the $\mathrm{H}_{2} / \mathrm{O}_{2} / \mathrm{N}_{2}$ flame with composition $3 / 1 / 3.7$. The flame speed versus methane concentration data were interpolated from the curves given by Miller et al (Ref. 35).

16. Variation of reciprocal H-atom concentration with time from reaction zone for the flame systems indicated in Table II. The $\mathrm{SO}_{2}$ data are from Kallend (Ref. 37). 


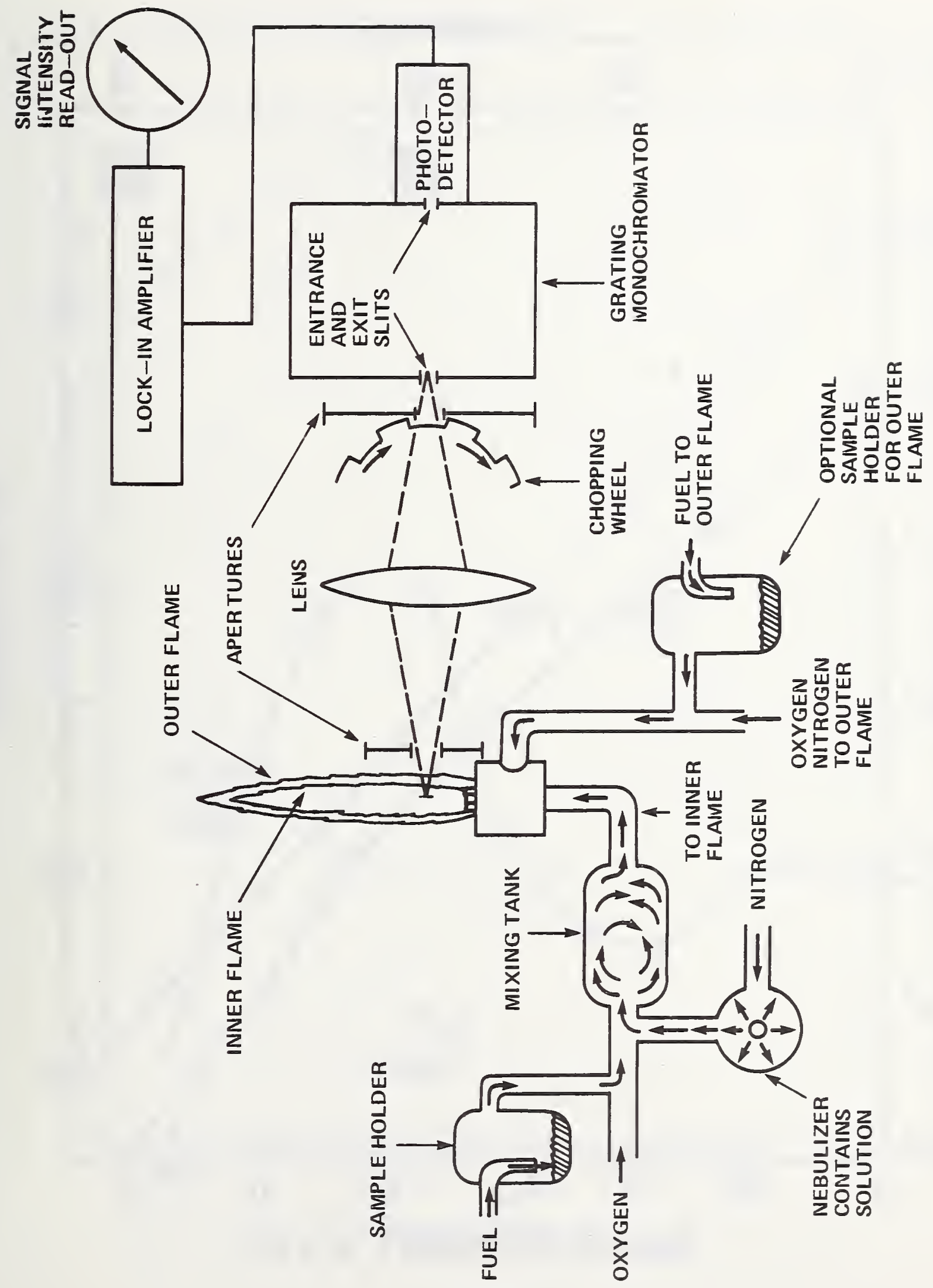


— TEMPERATURE ${ }^{\circ} \mathrm{C}$

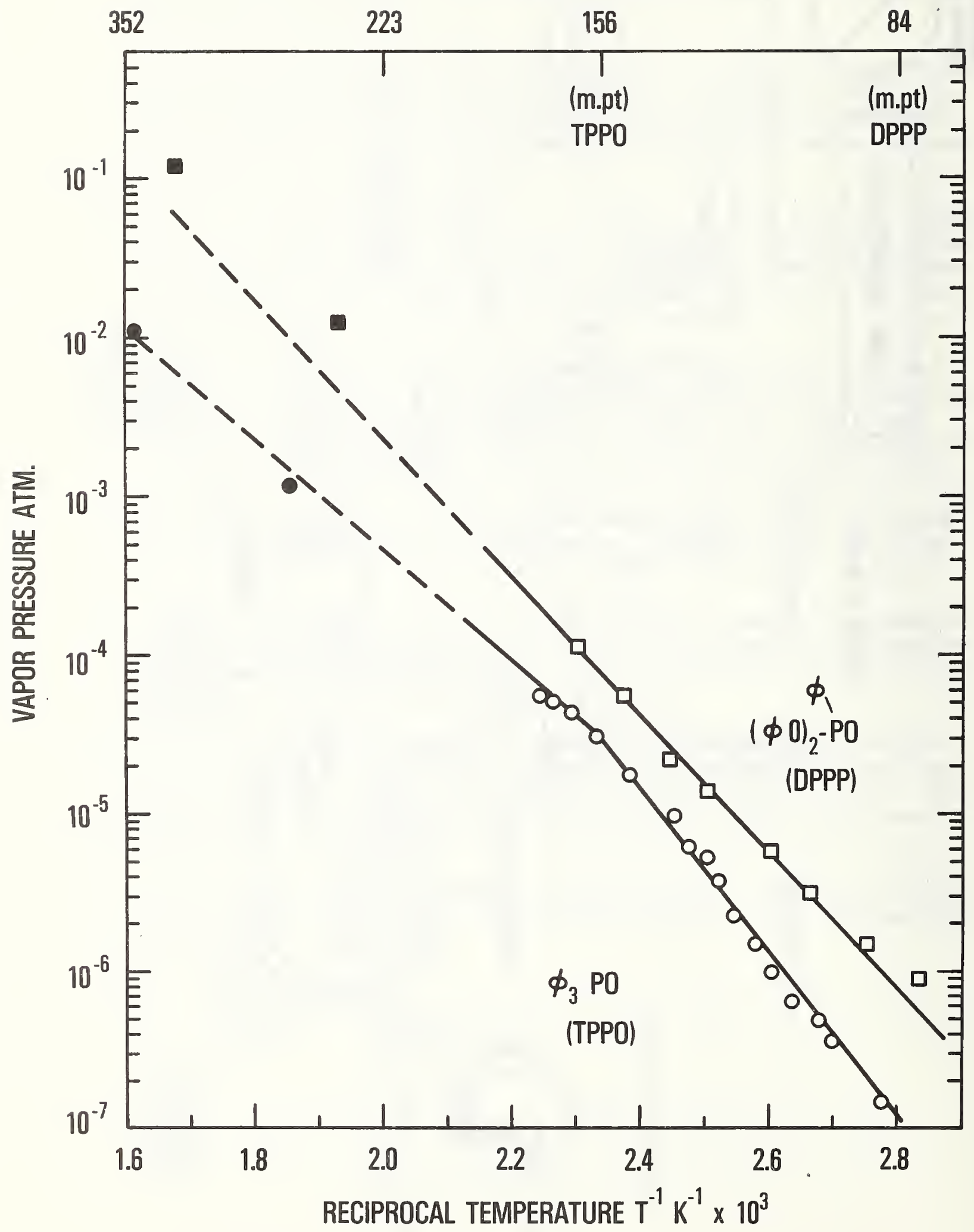




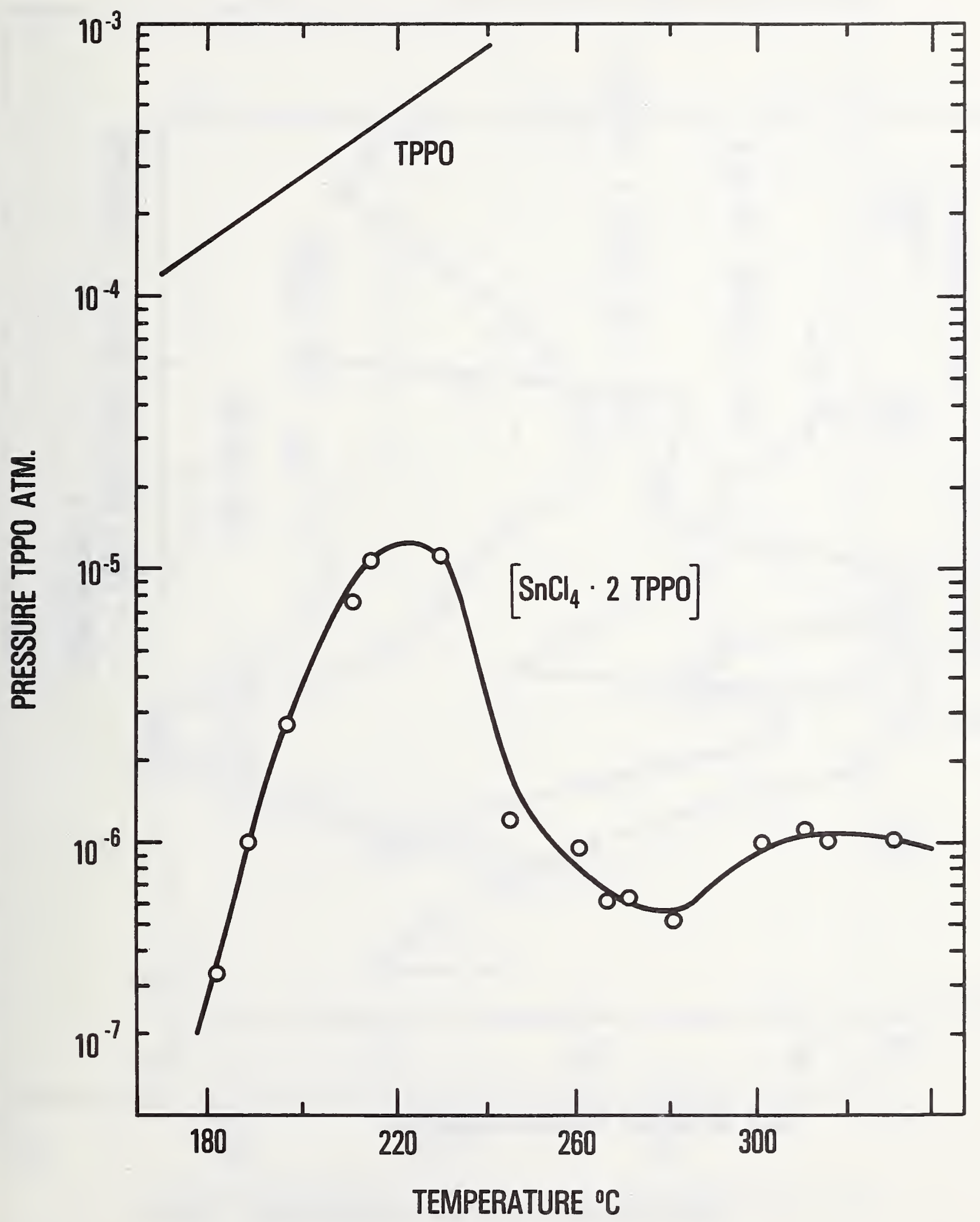

FIGURE 3 


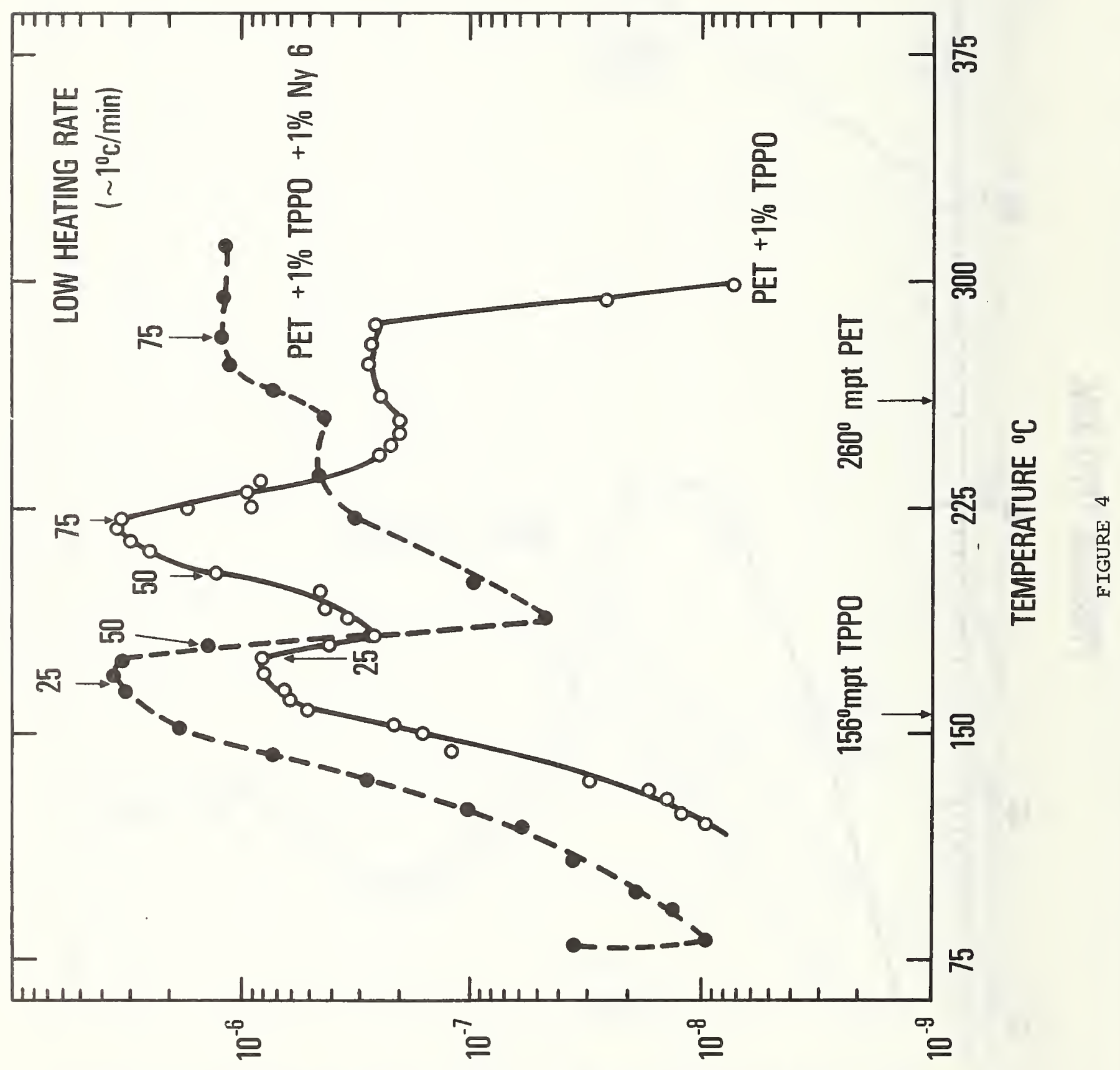

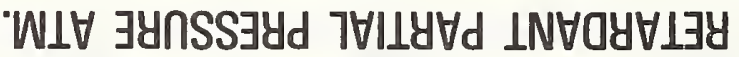




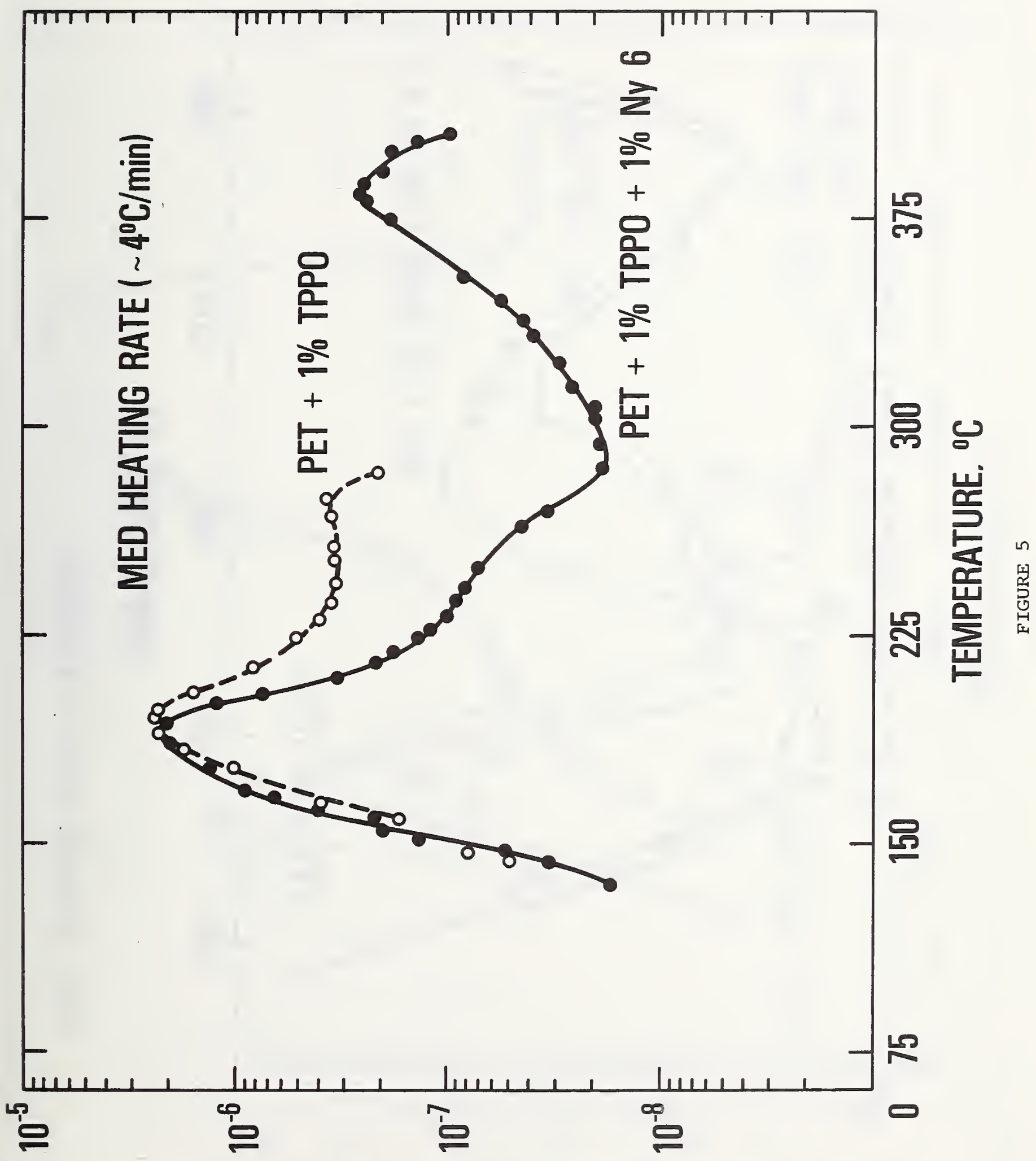

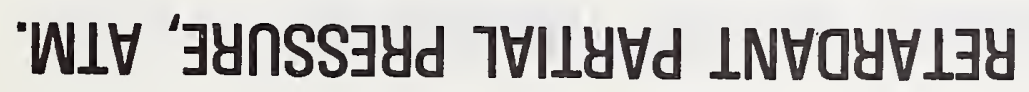




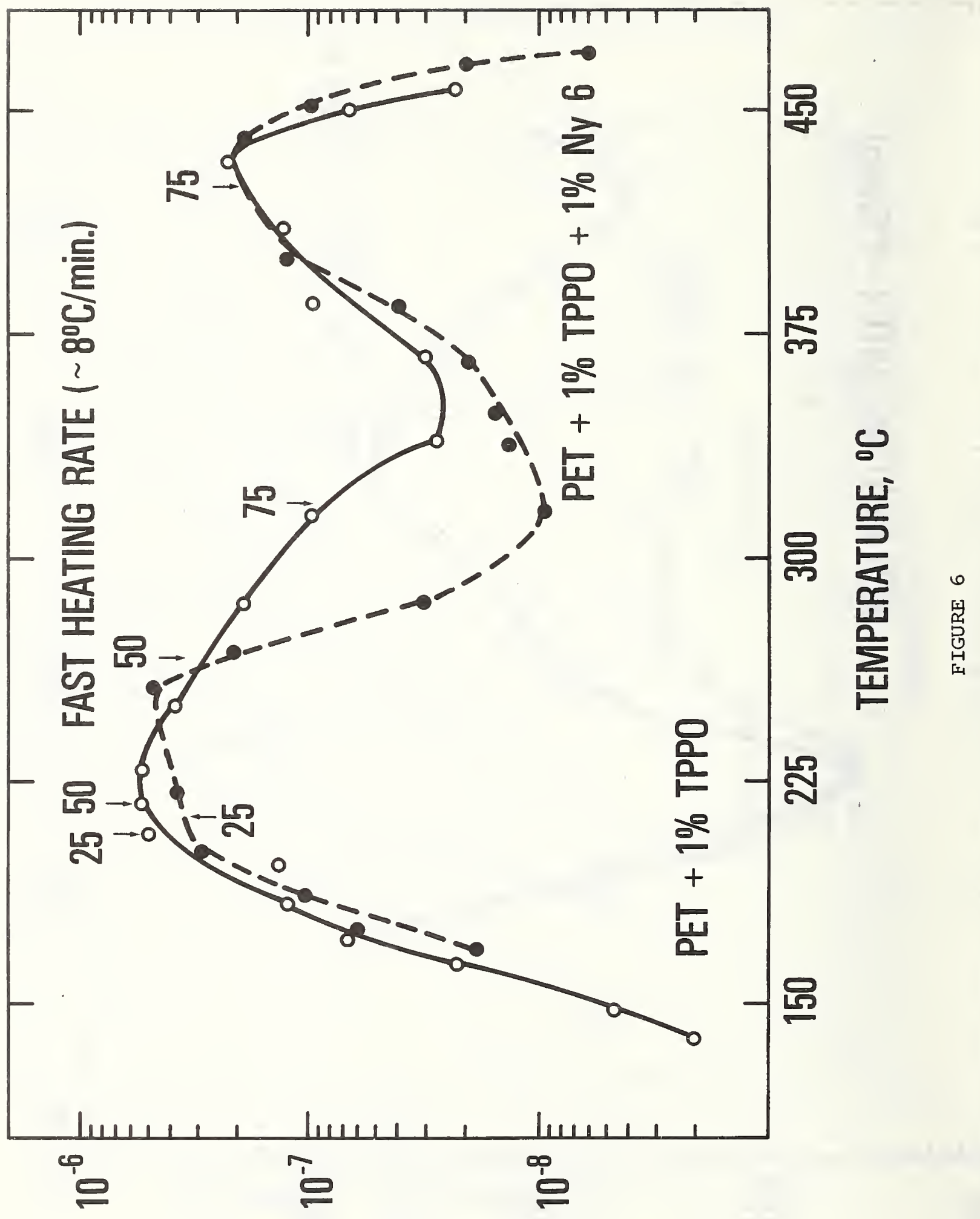

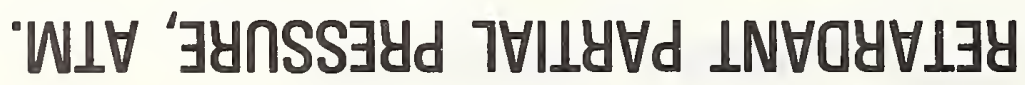




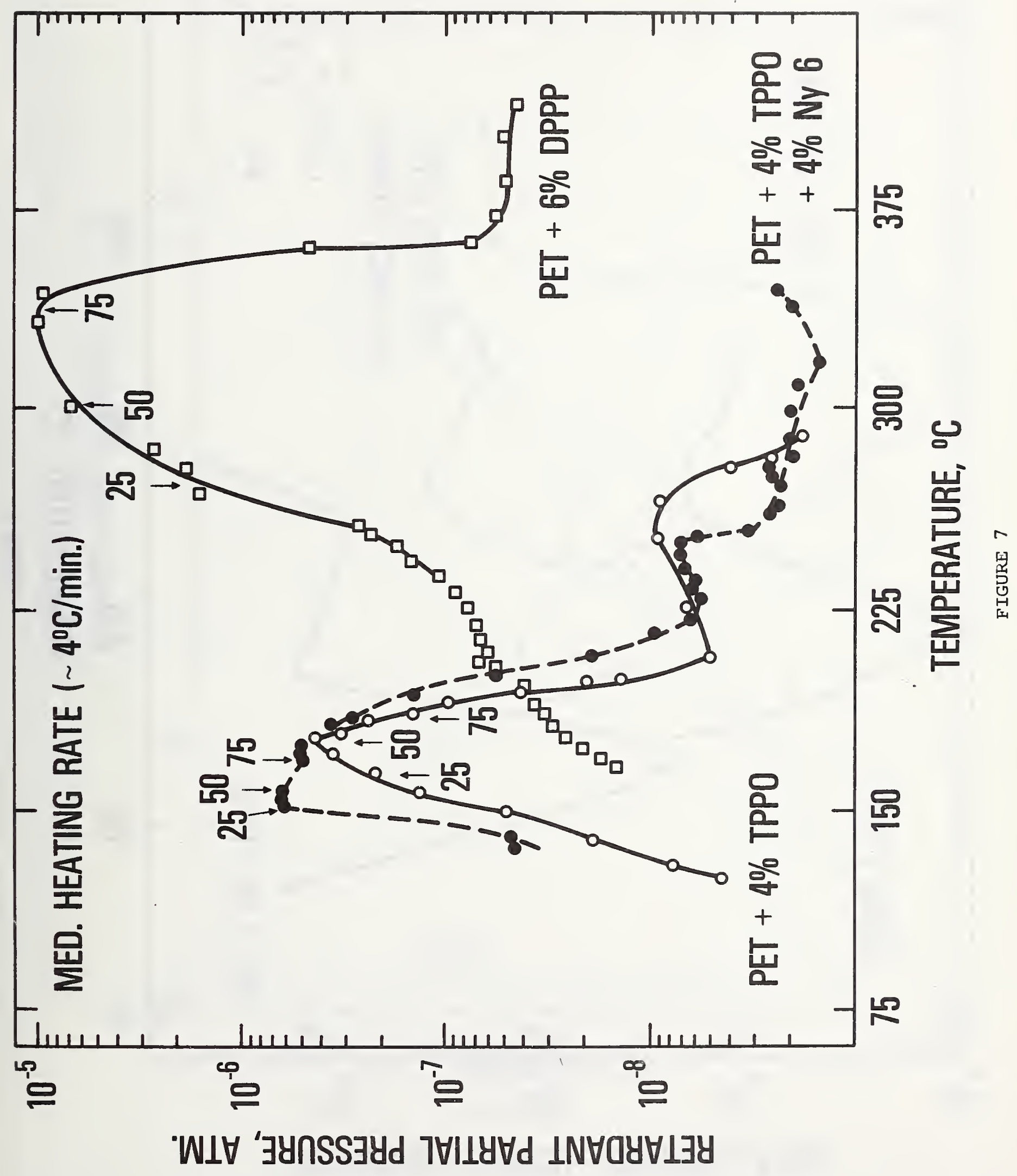




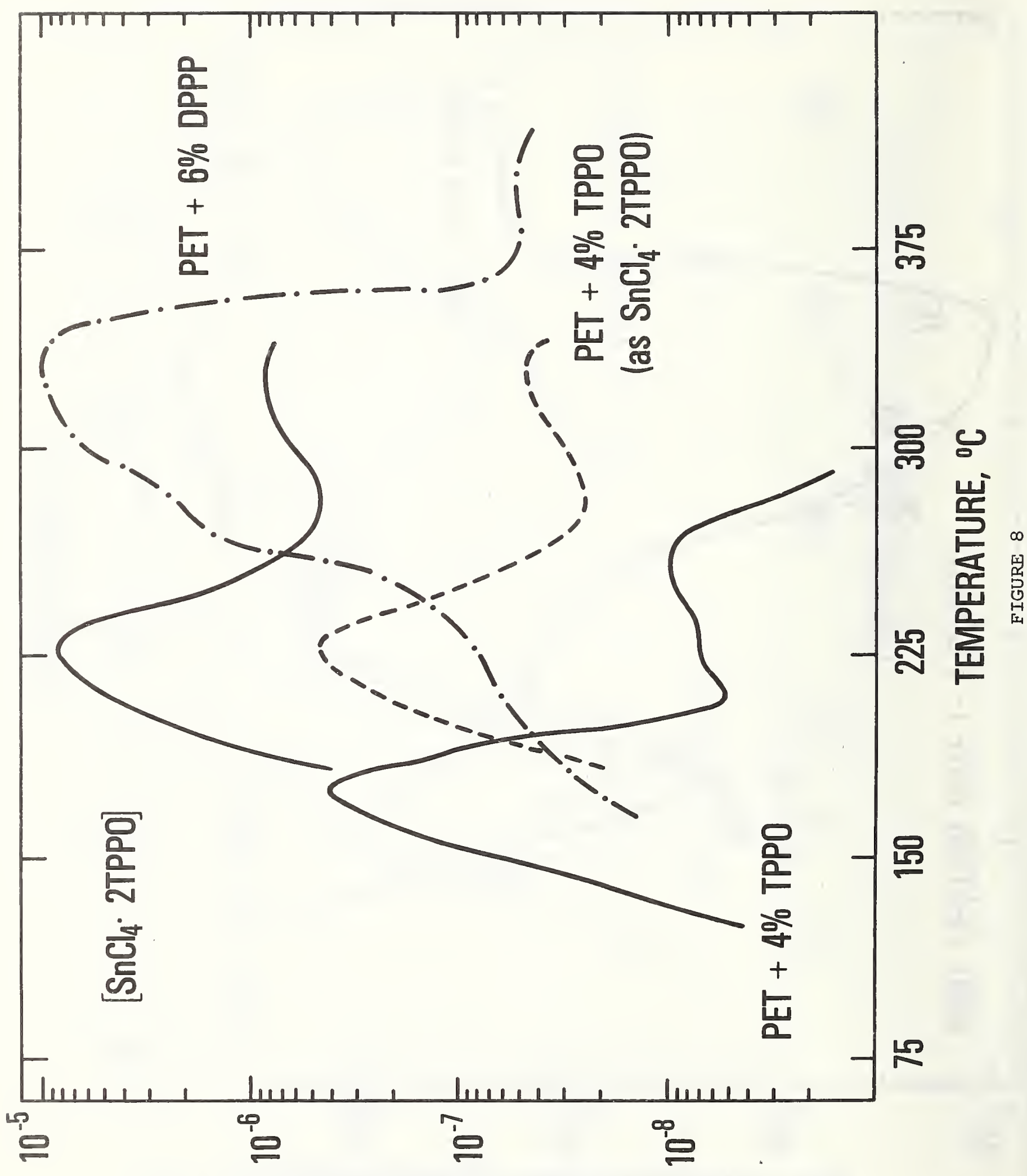

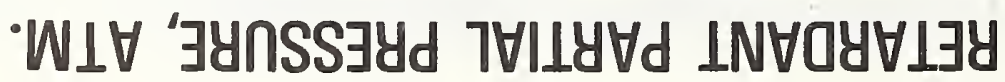




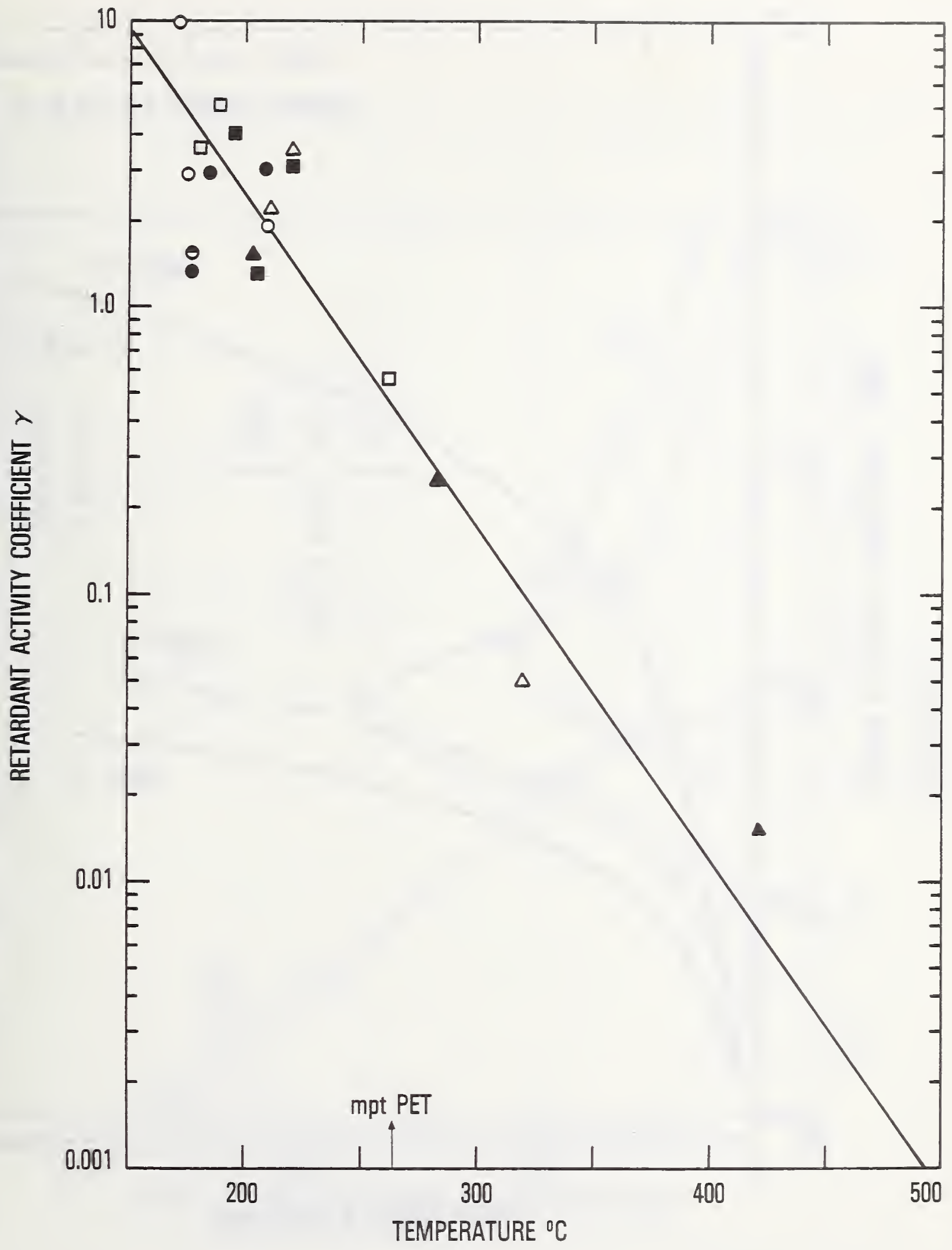

FIGURE 9 


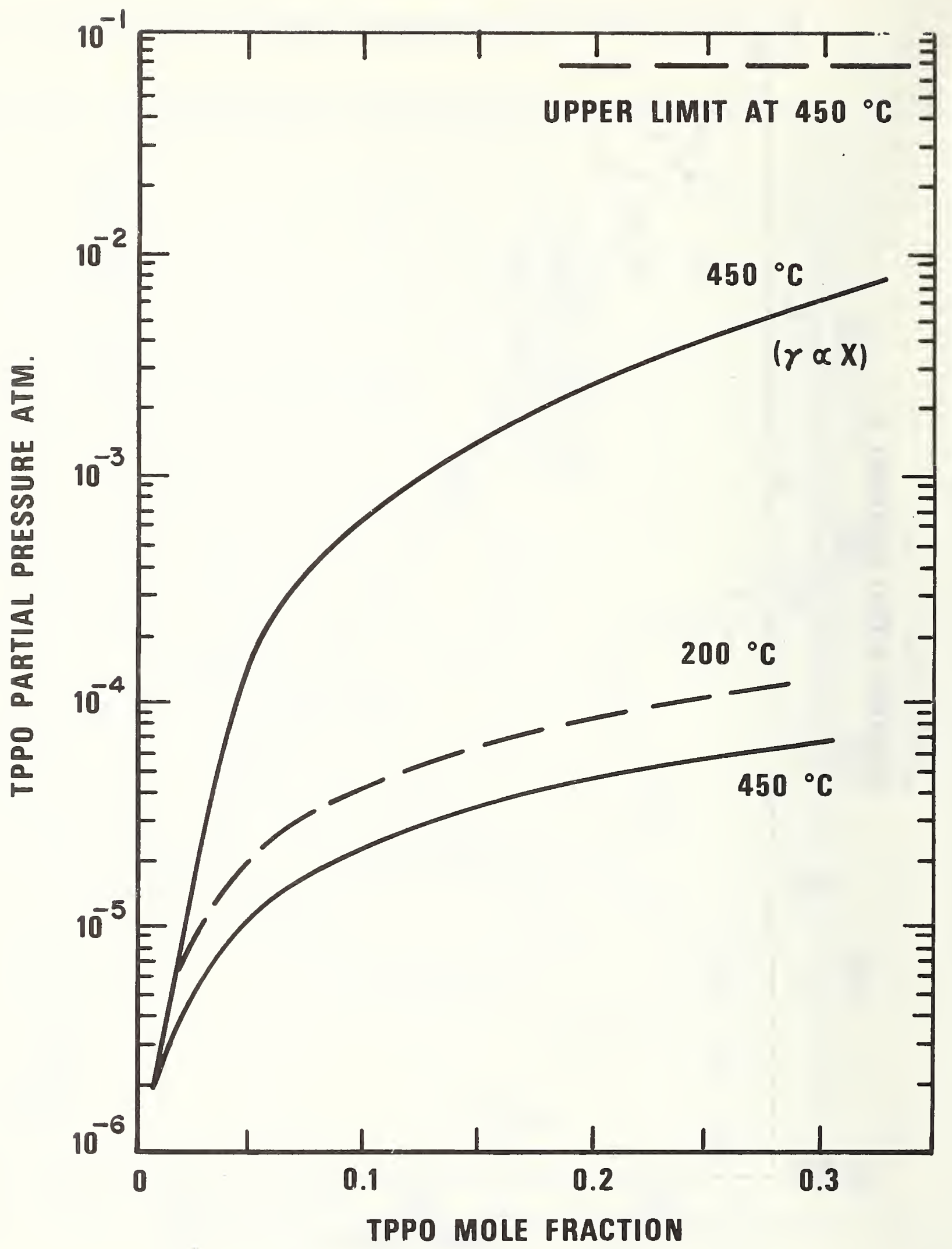

FIGURE 10 


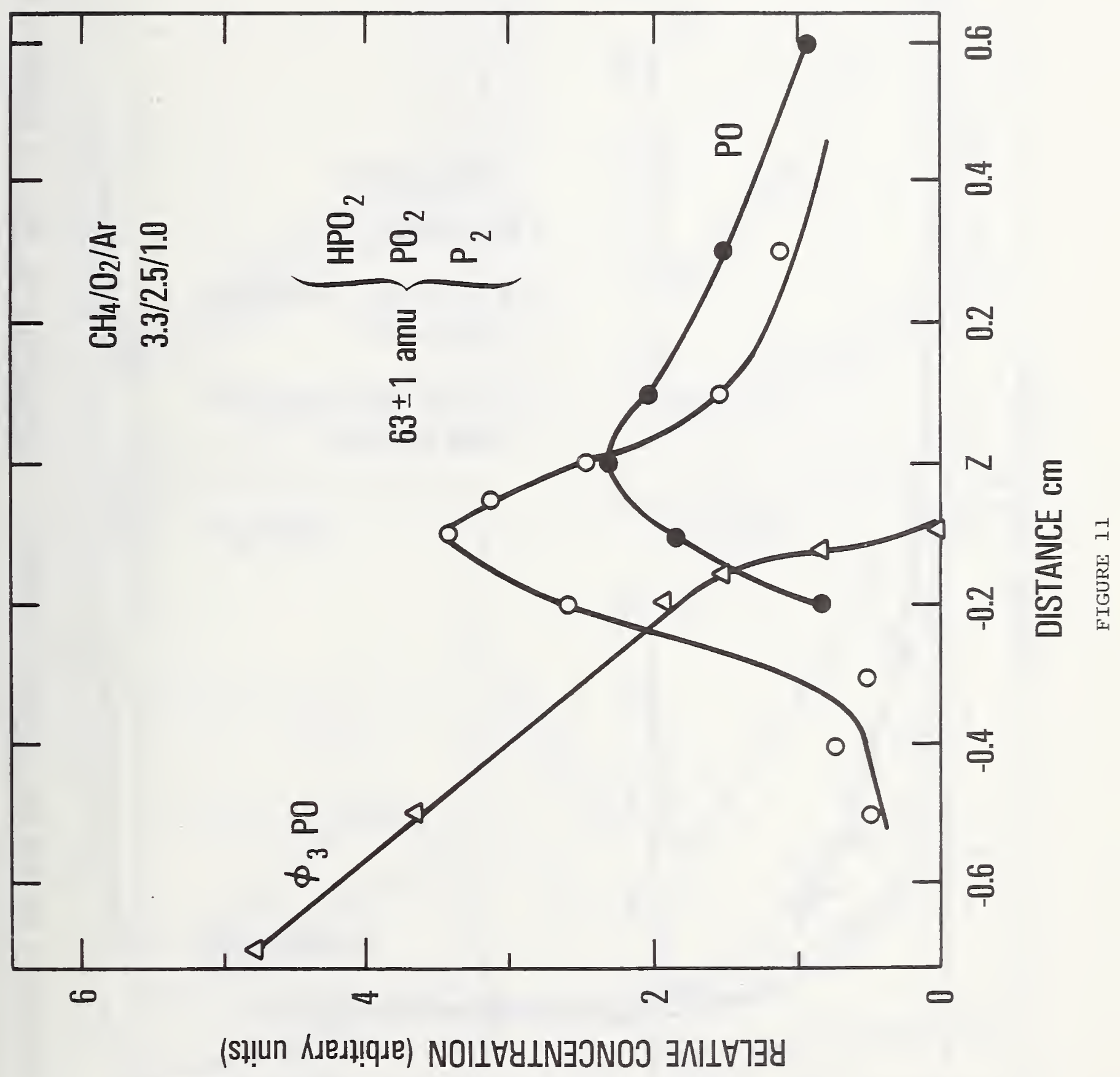




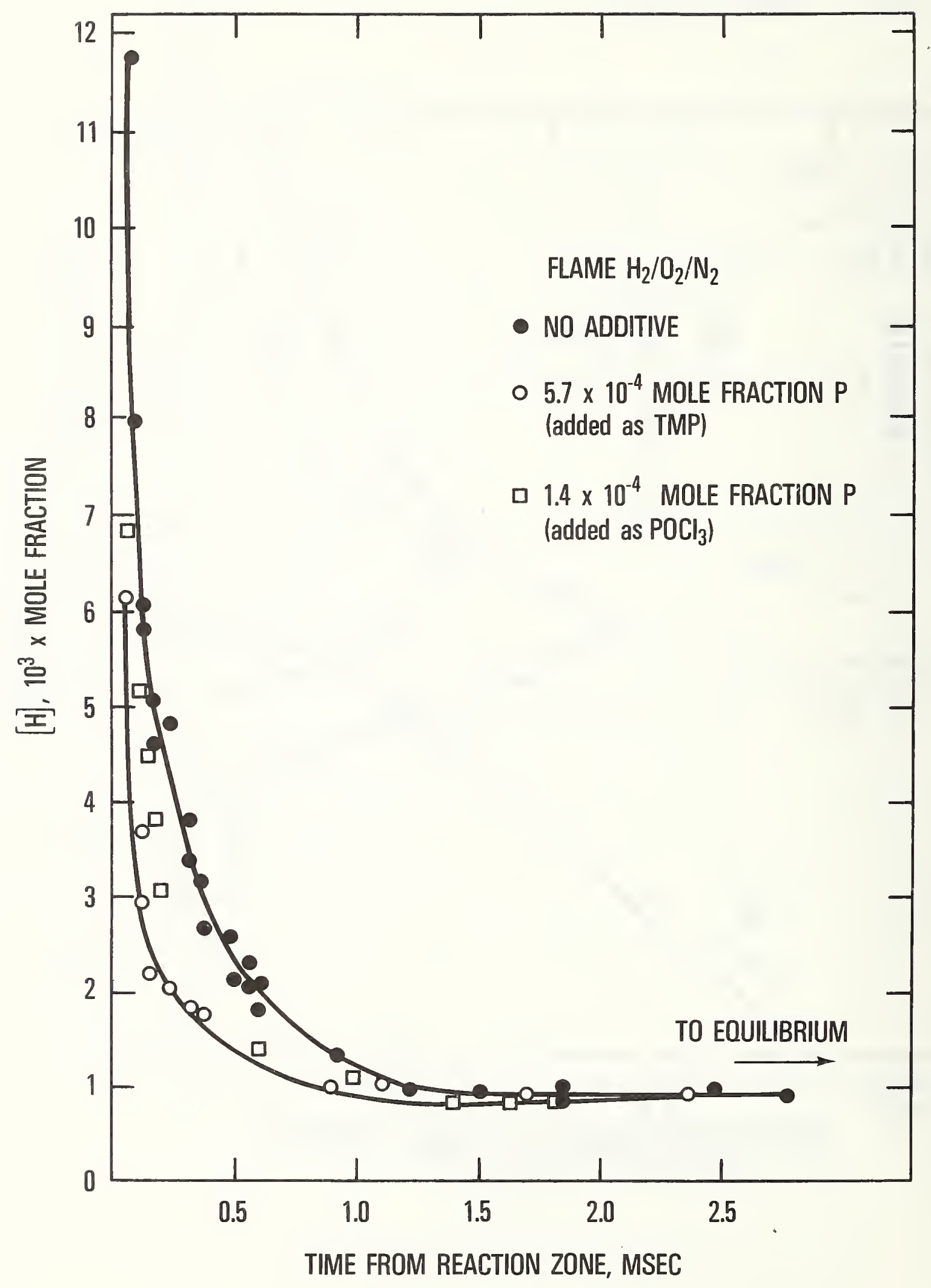

FIGURE 12 

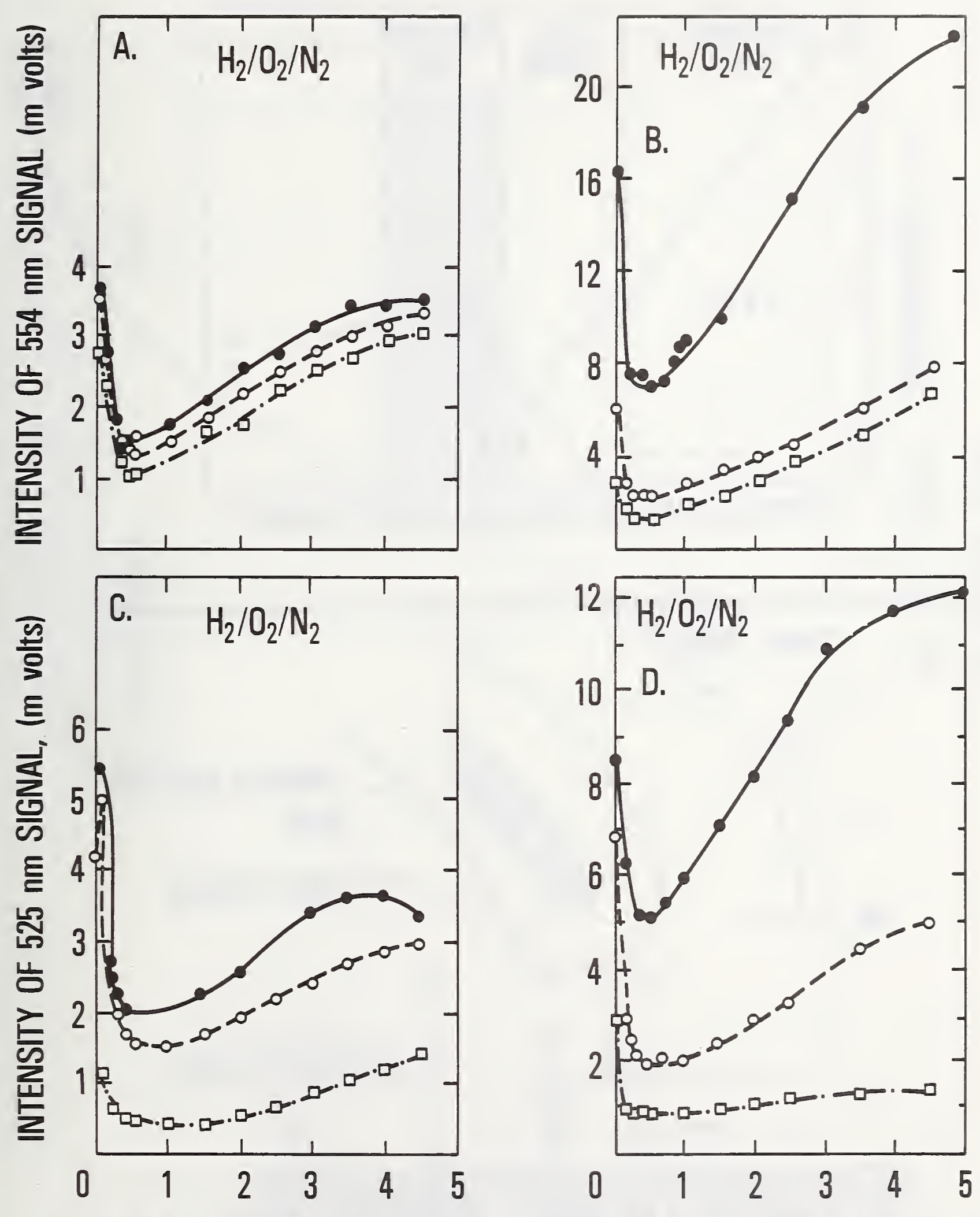

DISTANCE FROM BURNER, cm

DISTANCE FROM BURNER, $\mathrm{cm}$ 


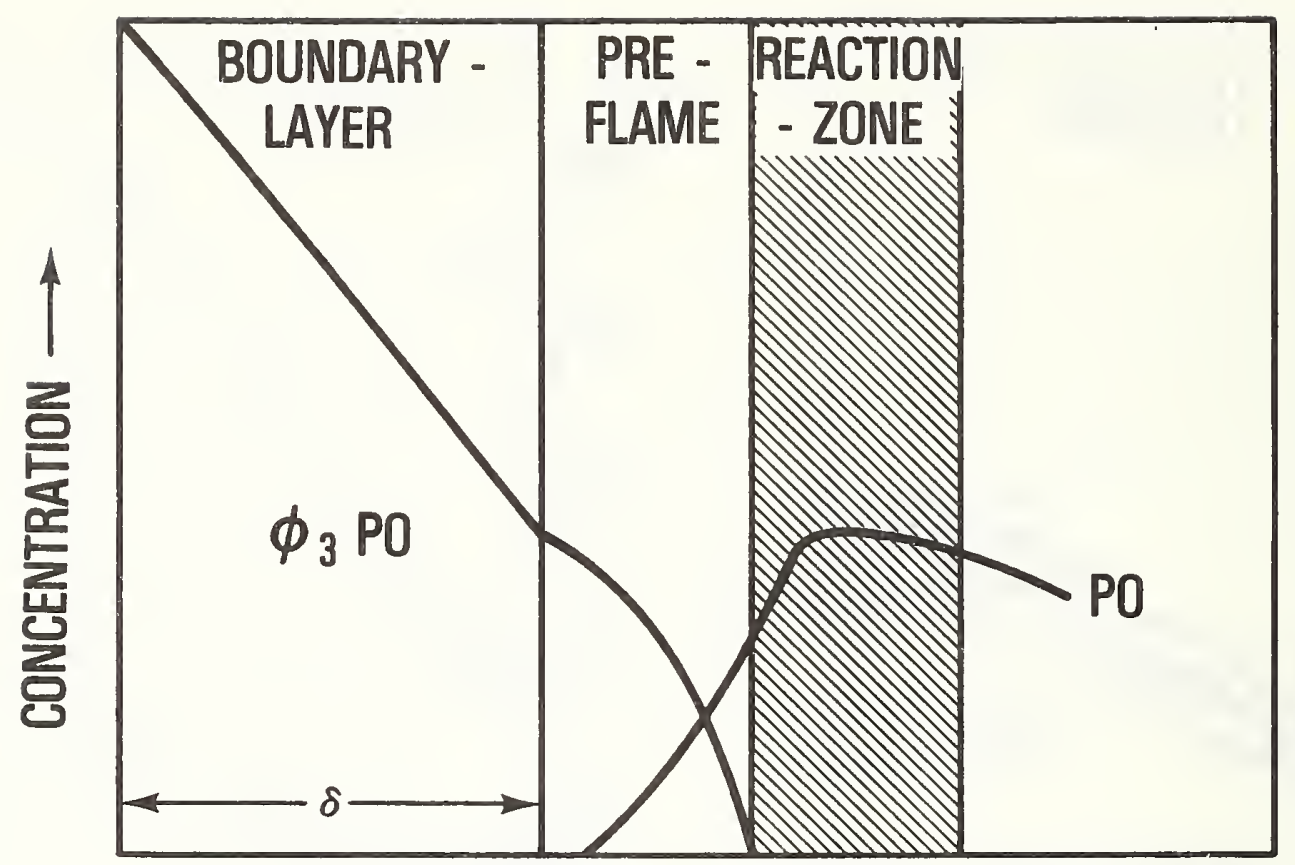

VERTICAL DISTANCE FROM SUBSTRATE SURFACE

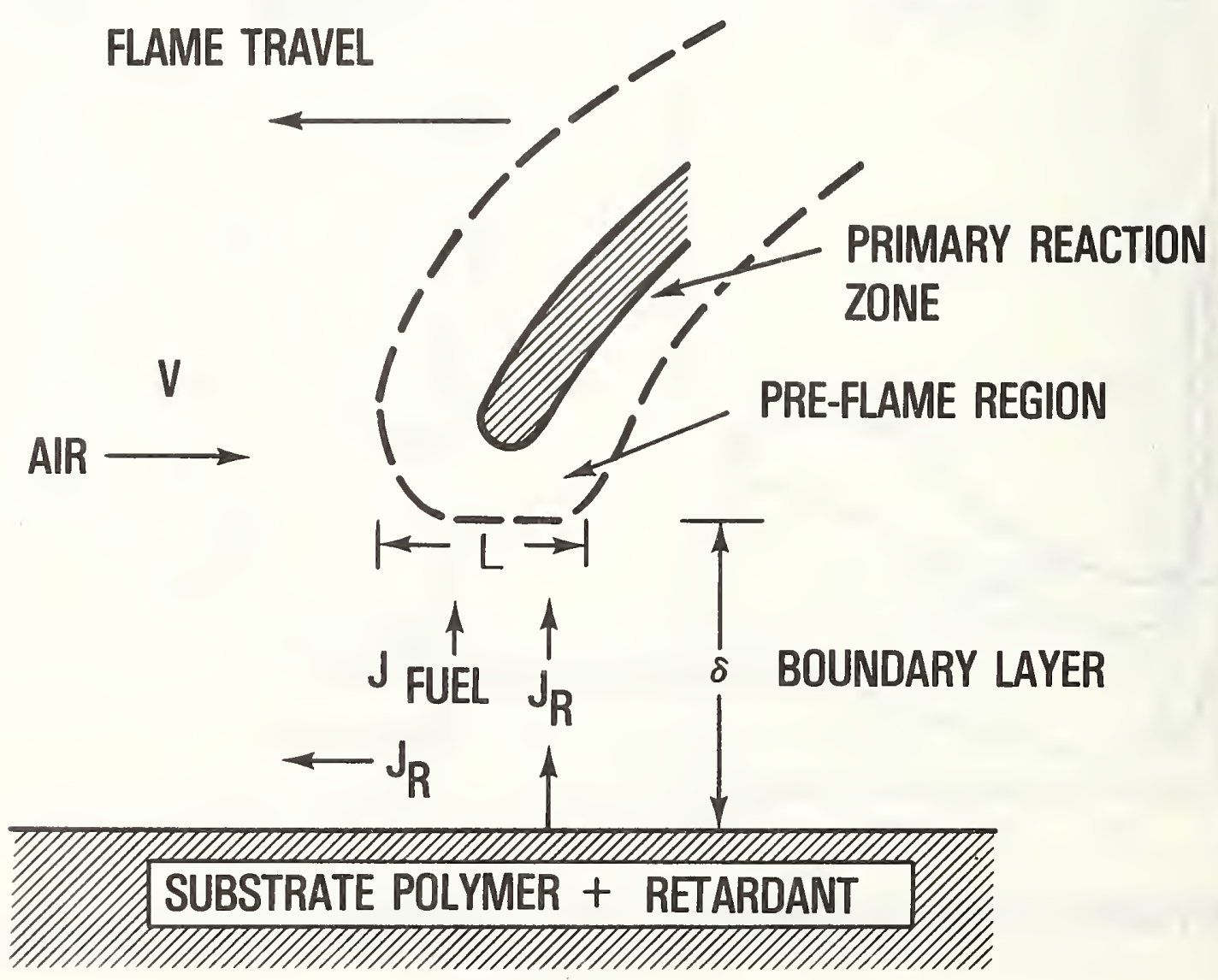




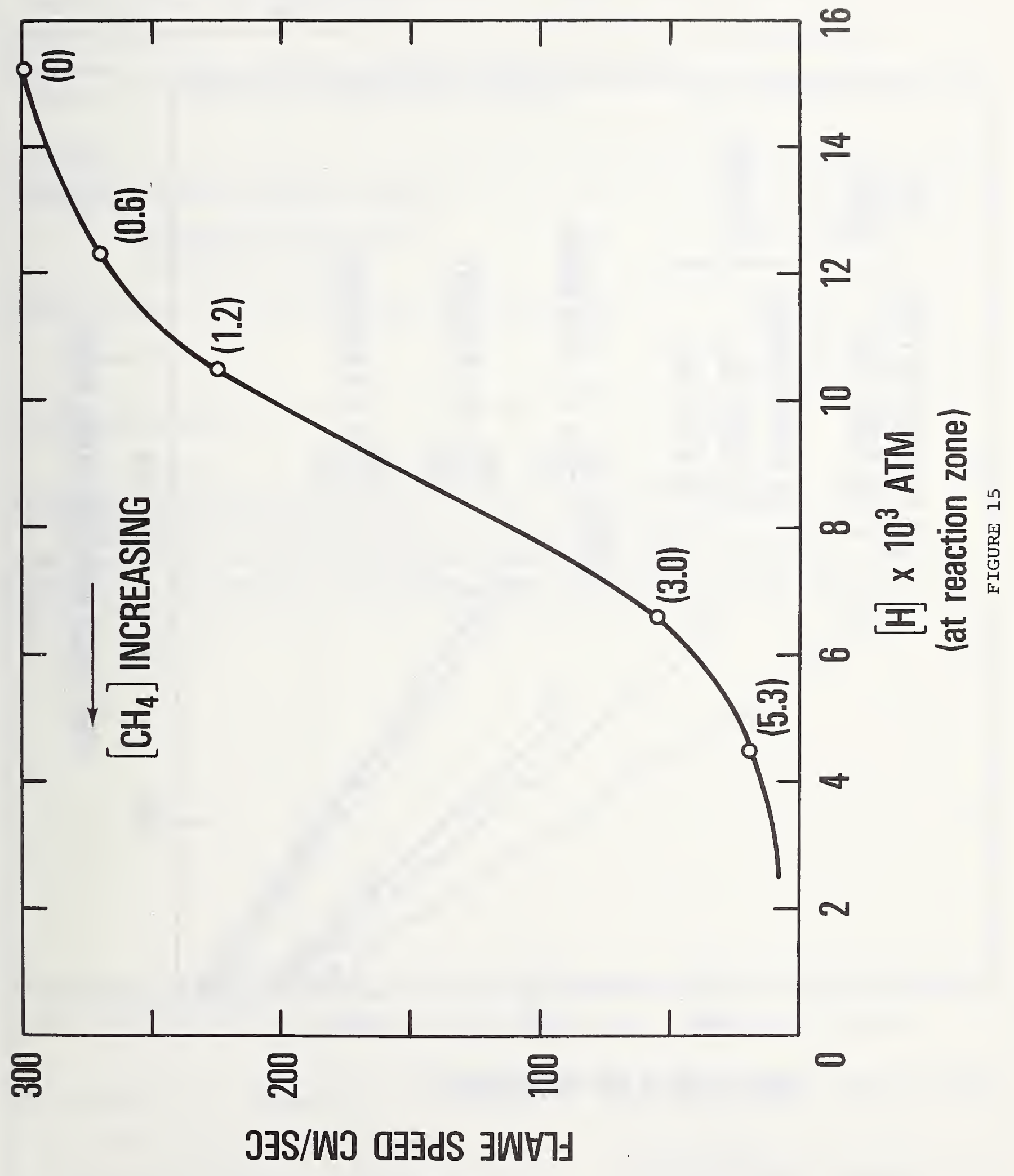




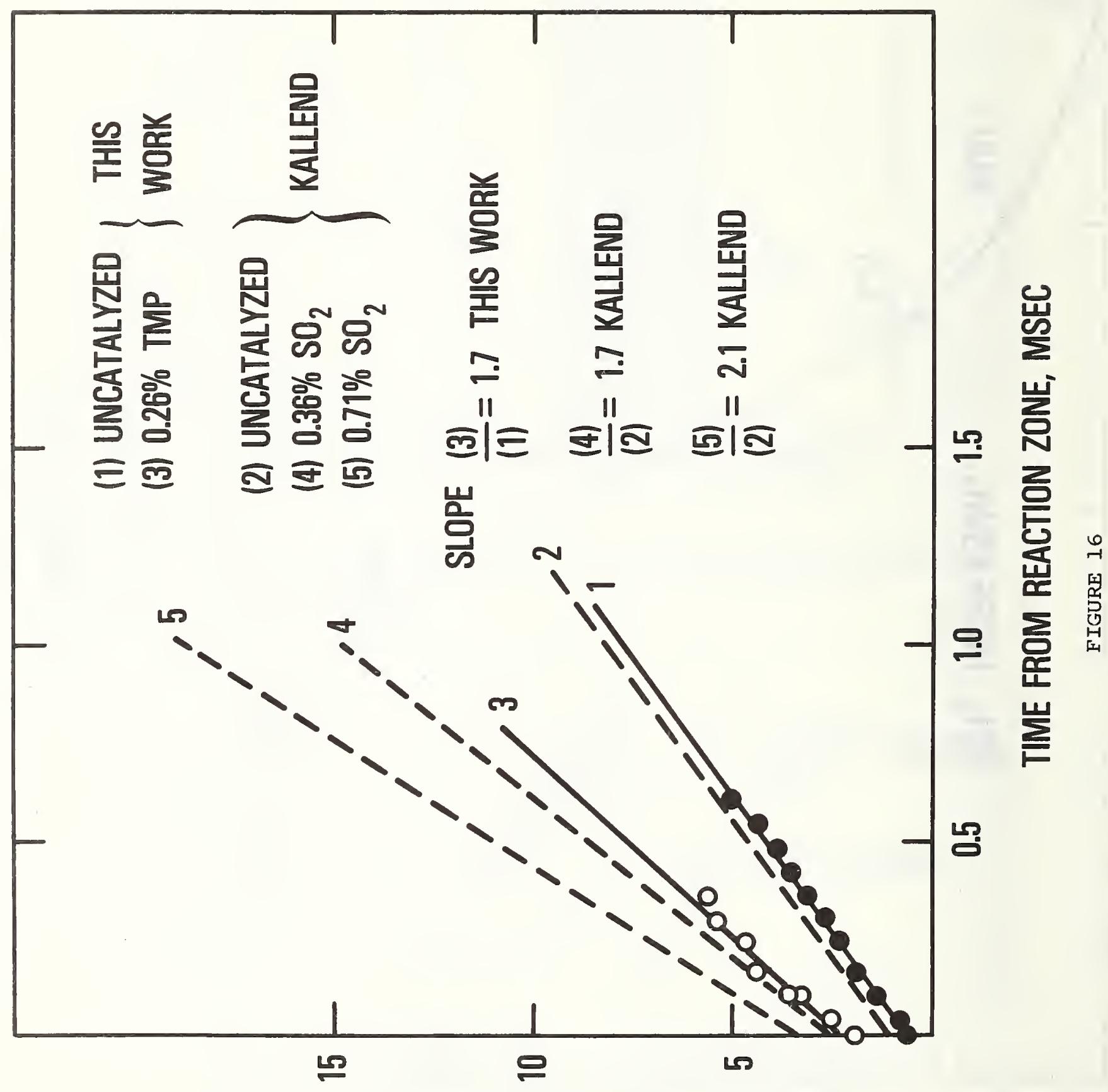

I-WIV' $2-0 L \times(H) 7 \forall J 0 y d I J \exists y$ 
NBS.114A (REV. 7.73 )

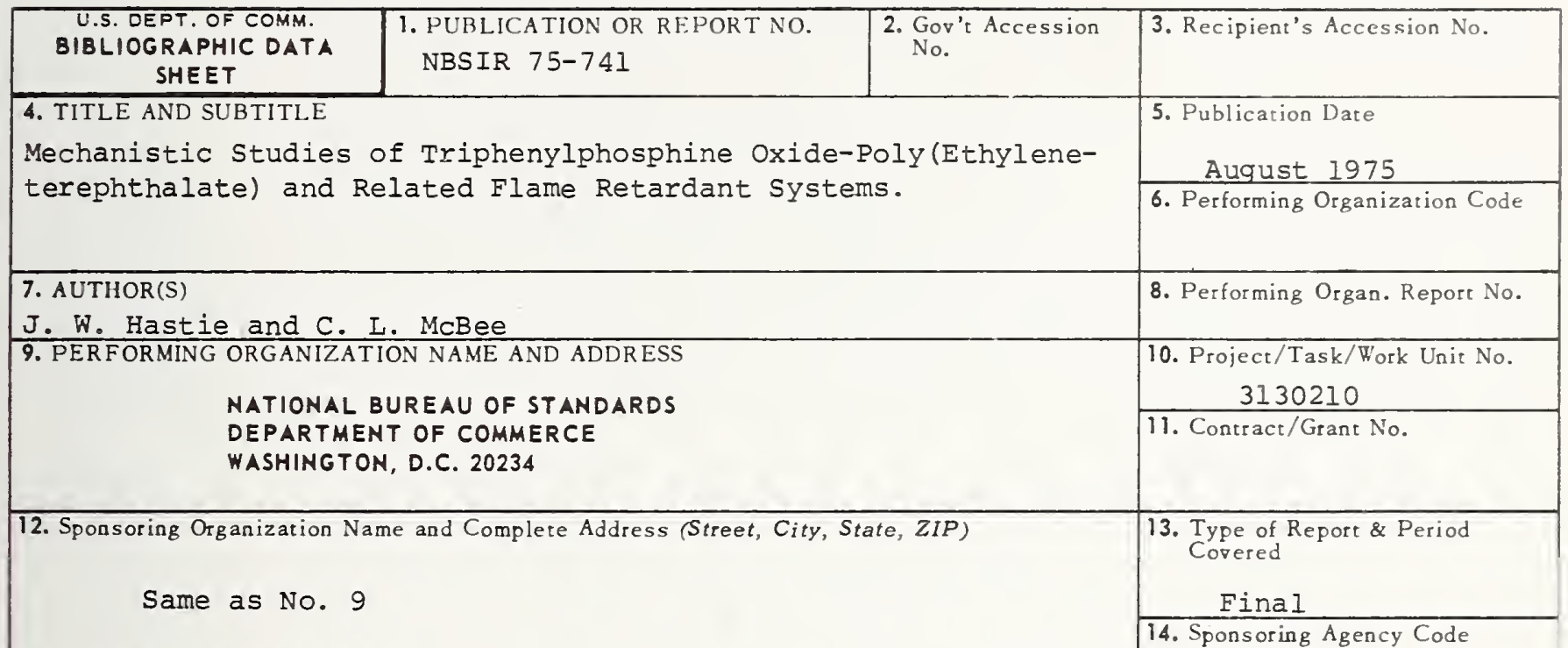

\section{SUPPLEMENTARY NOTES}

16. ABSTRACT (A 200-word or less factual summary of most significant in formation. If document includes a significant bibliography or literature survey, mention it here.)

A combination of mass spectrometric and optical spectroscopic studies has been made to establish a mechanism for phosphorus controlled flame retardancy in thermoplastics. It is shown that a vapor phase mode of flame inhibition can account for the known flame retardancy effect of triphenylphosphine-oxide in polyester substrates.

17. KEY WORDS (six to twelve entries; alphabetical order; capitalize only the first letter of the first key word unless a proper name; separated by semicolons)

Flame retardancy; mass spectrometry; optical spec troscopy; phosphorus; polyester

\section{AVAILABILITY [zzUnlimited}

For Official Distribution. Do Not Release to NTIS

Order From Sup. of Doc., U.S. Government Printing Office

Washington, D.C. 20402, SD Cat. No. C13

$\square$ Order From National Technical Information Service (NTIS) Springfield, Virginia 22151

\begin{tabular}{|l|c|}
\hline $\begin{array}{l}\text { 19. SECURITY CLASS } \\
\text { (THIS REPURT) } \\
\text { UNCLASSIFIED }\end{array}$ & 21. NO. OF PAGES \\
\hline $\begin{array}{l}\text { 20. SECURITY CLASS } \\
\text { (THIS PAGE) } \\
\text { UNCLASSIFIED }\end{array}$ & 22. Price \\
\hline
\end{tabular}





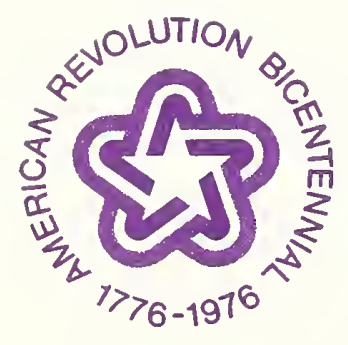

